\title{
Evaluation of the impact of strengthening Union Health and Family Welfare Centers for providing 24/7 normal delivery services in Bangladesh
}

Md. Noorunnabi Talukder

Population Council

A.K.M. Zafar Ullah Khan

Population Council

Mohammed Sharif

Forhana Rahman Noor

Population Council

Surojit Kundu

Population Council

See next page for additional authors

Follow this and additional works at: https://knowledgecommons.popcouncil.org/departments_sbsr-rh

Part of the Demography, Population, and Ecology Commons, Family, Life Course, and Society

Commons, International Public Health Commons, and the Maternal and Child Health Commons

How does access to this work benefit you? Let us know!

\section{Recommended Citation}

Talukder, Md. Noorunnabi, A.K.M. Zafar Ullah Khan, Mohammed Sharif, Forhana Rahman Noor, Surojit Kundu, Shongkour Roy, Afsana Fatema Noor, and Ubaidur Rob. 2016. "Evaluation of the impact of strengthening Union Health and Family Welfare Centers for providing 24/7 normal delivery services in Bangladesh," Technical report. Dhaka: Population Council. 


\section{Authors}

Md. Noorunnabi Talukder, A.K.M. Zafar Ullah Khan, Mohammed Sharif, Forhana Rahman Noor, Surojit Kundu, Shongkour Roy, Afsana Fatema Noor, and Ubaidur Rob 


\section{Evaluation of the Impact of Strengthening Union Health and Family Welfare Centers for Providing 24/7 Normal Delivery Services in Bangladesh}

MD. NOORUNNABI TALUKDER

A.K.M. ZAFAR ULLAH KHAN MOHAMMED SHARIF FORHANA RAHMAN NOOR

SUROJIT KUNDU

SHONGKOUR ROY AFSANA FATEMA NOOR UBAIDUR ROB 


\title{
Evaluation of the Impact of Strengthening Union Health and Family Welfare Centers for Providing 24/7 Normal Delivery Services in Bangladesh
}

\author{
MD. NOORUNNABI TALUKDER \\ A.K.M. ZAFAR ULLAH KHAN \\ MOHAMMED SHARIF \\ FORHANA RAHMAN NOOR \\ SUROJIT KUNDU \\ SHONGKOUR ROY \\ AFSANA FATEMA NOOR \\ UBAIDUR ROB
}
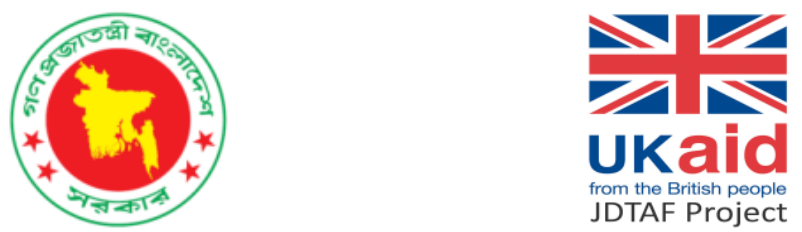

POPULATION COUNCIL

Ideas. Evidence. Impact. 


\section{popountron \\ Ideas. Evidence. Impact.}

The Population Council confronts critical health and development issues-from stopping the spread of HIV to improving reproductive health and ensuring that young people lead full and productive lives. Through biomedical, social science, and public health research in 50 countries, we work with our partners to deliver solutions that lead to more effective policies, programs, and technologies that improve lives around the world. Established in 1952 and headquartered in New York, the Council is a nongovernmental, nonprofit organization governed by an international board of trustees.

Population Council

Bangladesh Country Office

House 15B, Road 13, Gulshan 1

Dhaka 1212, Bangladesh

\section{Email: info.bangladesh@popcouncil.org}

popcouncil.org

Suggested citation: Talukder, M.N., A.K.M.Z.U. Khan, M. Sharif, F.R. Noor, S. Kundu, S. Roy, A.F. Noor, U. Rob. 2016. "Evaluation of the Impact of Strengthening Union Health and Family Welfare Centers for Providing 24/7 Normal Delivery Services in Bangladesh." Dhaka, Bangladesh: Population Council. 


\section{Table of Contents}

Table of Contents iii

List of Abbreviations $\quad$ iv

List of Tables and Figures $\quad$ V

Acknowledgments $\quad$ vi

Summary vii

I Introduction 1

II Project Description 2

III Methodology 3

IV Implementation of the Project 6

V Impact of the Interventions 9

$\begin{array}{lr}\text { Knowledge on Maternal Health Care Services } & 9\end{array}$

$\begin{array}{ll}\text { Utilization of Antenatal Care Services } & 13\end{array}$

$\begin{array}{ll}\text { Utilization of Delivery Services } & 17\end{array}$

$\begin{array}{ll}\text { Utilization of Postnatal Care Services } & 27\end{array}$

Use of Contraception $\quad 30$

$\begin{array}{ll}\text { Provider Competence } & 31\end{array}$

$\begin{array}{lll}\text { VI } & \text { Program Effectiveness } & 34\end{array}$

VII Stakeholders' Views 38

$\begin{array}{lll}\text { VIII } & \text { Cost Analysis } & 46\end{array}$

$\begin{array}{lll}\text { IX Discussions and Conclusions } & 49\end{array}$

$\begin{array}{ll}\text { References } & 54\end{array}$

$\begin{array}{ll}\text { Appendixes } & 55\end{array}$ 


\section{List of Abbreviations}

\begin{tabular}{|c|c|}
\hline ANC & Antenatal Care \\
\hline $\mathrm{BCC}$ & Behavior Change Communication \\
\hline BDT & Bangladesh Taka \\
\hline $\mathrm{CHCP}$ & Community Health Care Provider \\
\hline CSBA & Community Skilled Birth Attendant \\
\hline DDFP & Deputy Director of Family Planning \\
\hline DFID & Department for International Development \\
\hline DGFP & Directorate General of Family Planning \\
\hline DGHS & Directorate General of Health Services \\
\hline EDD & Expected Date of Delivery \\
\hline EmOC & Emergency Obstetric Care \\
\hline FP & Family Planning \\
\hline FGD & Focus Group Discussion \\
\hline FWA & Family Welfare Assistant \\
\hline FWV & Family Welfare Visitor \\
\hline $\mathrm{HR}$ & Human Resources \\
\hline JDTAF & Joint Donor Technical Assistance Fund \\
\hline LGI & Local Government Institute \\
\hline $\mathrm{MCH}$ & Maternal and Child Health \\
\hline $\mathrm{MC} \& \mathrm{RH}$ & Maternal and Child \& Reproductive Health \\
\hline MCWC & Mother and Child Welfare Center \\
\hline $\mathrm{MO}-\mathrm{MCH}$ & Medical Officer-Maternal and Child Health \\
\hline NGO & Non-governmental Organization \\
\hline $\mathrm{OR}$ & Operations Research \\
\hline OOP & Out-of-pocket \\
\hline PNC & Postnatal Care \\
\hline PRA & Participatory Rural Appraisal \\
\hline QA & Quality Assurance \\
\hline SACMO & Sub-Assistant Community Medical Officer \\
\hline TA & Technical Assistance \\
\hline TBA & Traditional Birth Attendant \\
\hline $\mathrm{UHC}$ & Upazila Health Complex \\
\hline UHFWC & Union Health and Family Welfare Center \\
\hline UHFWCMC & UHFWC Management Committee \\
\hline UNO & Upazila Nirbahi officer \\
\hline
\end{tabular}




\section{List of Tables and Figures}

Table 2.1 Study design 2

Table $5.1 \quad$ Knowledge on sources of pregnancy care in the locality over time (in percent) 9

Table 5.2 Respondent's knowledge regarding problems to receive services from UHFWC by the women 11 in the community (in percent)

Table 5.3 Knowledge regarding sources of treatment for delivery complications (in percent) 12

Table 5.4 Changes in uptake of antenatal care services (in percent) 13

Table 5.5 Changes in uptake of first antenatal care services by facility (in percent) 14

Table 5.6 Quality of care score for antenatal care services (score 0-1) 16

Table 5.7 Changes in uptake of delivery services by facility (in percent) 17

Table 5.8 Changes in uptake of delivery services by type and provider (in percent) 18

Table 5.9 Changes in uptake of delivery complications management care by sources of treatment (in 19 percent)

Table 5.10 Referral places from where delivery complications care received (in percent) 20

Table 5.11 Changes in average expenditure pattern for facility-based delivery services by facility type (in 21 Bangladesh Taka)

Table 5.12 Changes in average expenditure pattern for normal delivery services (in percent) 22

Table 5.13 Changes in average expenditure pattern for cesarean delivery services (in percent) 23

Table 5.14 Equity Ratio in uptake of delivery services over time 25

Table 5.15 Quality of care score for delivery services at public and private facilities (score 0-1) 26

Table 5.16 Changes in uptake of first postnatal care services (in percent) 27

Table 5.17 Changes in uptake of first postnatal care services by facility and type of provider (in percent) 28

Table 5.18 Quality of care score for postnatal care services (score 0-1) 29

Table 5.19 Changes in the use of family planning methods over time (in percent) 30

Table 5.20 Clinical skills of FWVs on maternal health care (in number) 33

Table 6.1 Sustainability score on community participation (score 0-1) 35

Table 6.2 Community contribution to 18 intervention UHFWCs (in number) 36

Table 6.3 Respondent's knowledge regarding UHFWC Management Committee and Community Fund 36 (in percent)

Table 6.4 Physical improvement and service improvement of UHFWCs in the last one year reported by respondents (in percent)

Table 6.5 Reasons for low use of UHFWCs for deliveries among women who sought ANC (in percent) 37

Table 8.1 Change in number of users of maternal health services at UHFWCs due to interventions 46

Table 8.2 Amount of community contribution as percentage of total cost of the interventions 48

Figure 5.1 Respondent's knowledge regarding services provided at the UHFWC over time (in percent) 10

Figure 5.2 Changes in uptake of antenatal care services by type of provider (in percent) 15

Figure 5.3 Counseling skills of FWVs on maternal health services (score 0-1) 31

Figure 5.4 Knowledge of FWVs on possible complications during pregnancy, during delivery, and after 32 delivery (score $0-1$ )

Figure 8.1 Basic estimates of cost incurred by the project 47 


\section{Acknowledgments}

The Population Council would like to express sincere gratitude to the Department for International Development (DFID) for the financial assistance for the project "Strengthening Union Health and Family Welfare Centers for Providing Round-the-Clock Normal Delivery Services" under which this evaluation report was prepared.

Special thanks are due to the district and upazila level government officials-Civil Surgeons, Deputy Directors of Family Planning (DDFP), Upazila Health and Family Planning Officers (UHFPO), Upazila Family Planning Officers (UFPO) and Medical Officers-Maternal and Child Health (MO-MCH), service providers and office support staff of respective study sites for their cooperation to conduct the survey. We are grateful to the fieldworkers who provided list of pregnant mothers and helped the research team in locating selected households. We are also thankful to the women who participated in the survey. In addition, we would like to thank the study team who were involved in the data collection process.

We are grateful to Dr. Mohammed Sharif, Director $(\mathrm{MCH})$ and Line Director ( $\mathrm{MC} \& \mathrm{RH})$, Directorate General of Family Planning (DGFP), Dr. Tapash Ranjan Das, Assistant Professor, Gopalgonj Medical College, Dr. Fahmida Sultana, Deputy Director, MCH, DGFP and Dr. Farid Uddin Ahmed, Deputy Director, MCH, DGFP for their guidance and cooperation at every step of the study.

We express our deep gratitude to the Planning Wing of the Ministry of Health and Family Welfare for approving the TA under JDTAF program. We gratefully acknowledge the contribution of Mr. Devashish Banerji, Program ManagerService Provider for JDTAF, Crown Agents Bangladesh in facilitating funding for the project.

Finally, we are thankful to Mr. Dipak Kumar Shil, Director of Administration, Finance and Human Resource at the Population Council Bangladesh office for the financial management of the project. 


\section{Summary}

In Bangladesh, the majority of the deliveries in rural areas take place at homes with higher risk of morbidity and mortality. Most Union Health and Family Welfare Centers (UHFWCs) do not have the provision to provide 24-hour normal delivery services which is in close proximity of most of the rural women. With this point of view, the Population Council has provided technical assistance to the Directorate General of Family Planning (DGFP) to implement an Operations Research (OR) study in 24 UHFWCs of Chittagong and Munshiganj districts to test the effectiveness of a model to strengthen UHFWCs so that they can provide 24-hour normal delivery services. Broadly, three interventions, namely, human resource strengthening, community participation, and referral linkage strengthening were implemented for 12 months. Six UHFWCs from Comilla district comparable to the intervention UHFWCs served as control sites. A separate sample pre-test and post-test control group design was used to evaluate the impact of the interventions.

Prior to the interventions, UHFWCs were widely known as a facility that provides family planning and mother and child care services, followed by general illness services. Interventions have resulted in improving the awareness of UHFWC's 24-hour normal delivery services among women (Chittagong: Baseline 6\%, Endline 40\%; Munshiganj: Baseline 0\%, Endline 31\%); yet, two-thirds of the women remain ignorant of UHFWC's 24/7 normal delivery services.

Seeking antenatal care (ANC) is almost universal in the intervention areas which remained the same in the past 12 months. In the intervention areas, of women who received ANC from public facilities, over 70 percent sought first ANC from local facilities (UHFWCs and Community Clinics) while 57 percent in the control district so reported. Findings also suggest a higher rate of institutional delivery in the intervention districts $(72 \%, 79 \%)$ than the control district (53\%). However, a stark difference exists between two intervention districts in terms of types of delivery. Women in Chittagong were more likely to undergo normal deliveries $(77 \%)$, while cesarean deliveries were more widespread in Munshiganj (58\%). The higher rate of cesarean deliveries in Munshiganj reveals weaknesses in the clinical monitoring mechanism of the government.

Of the intervention districts, the share of private facilities in institutional deliveries is much higher in Munshiganj (70\%) than in Chittagong (36\%). Despite the cost of receiving cesarean deliveries at private facilities is two times that at public facilities (BDT 23,485 vs. BDT 12,772), women in Munshiganj were more likely to use private facilities than public facilities, which suggests the better environment and quality of services at the private facilities. A composite quality score for client satisfaction on delivery services substantiates the women preference for private facilities. The public-private gap in client satisfaction on delivery services is evident in Munshiganj, in favor of private facilities (public: 0.66 , private: 0.75 ).

Qualitative findings explain the reasons for client preference for private facilities. People choose private hospitals over public hospitals as physical amenities, e.g., infrastructure, environment, cleanliness, equipment, supplies, and attendant accommodation, are better in private facilities. The unavailability of cesarean delivery provision at the UHFWCs and many upazila-level government facilities is the key supply-side problem that prompts women to go to private clinics. Enhanced economic condition of the people is largely accounted for client's preference for private facilities.

It is surprising to find that in some UHFWCs in Munshiganj delivery output has declined. Increasing the utilization of normal delivery services at many UHFWCs in Munshiganj has not been possible for a combined effect of geographic proximity to the government tertiary level hospital with good road communication, availability of private clinics at the union level, and the affordability of households to seek expensive care at private facilities.

Regardless of the intervention exposure, the utilization of postnatal care (PNC) increased remarkably (Chittagong: 54-75\%, Munshiganj: 46-78\%, Comilla: 26-54\%). The improvement in the utilization of PNC within two days after birth is encouraging which indicates that provider utilized the opportunity to perform postnatal check-ups immediately after birth. Among the public-sector facilities, low use of UHFWCs for PNC (Chittagong: 34\%, Munshiganj: 14\%, Comilla: 14\%) and non-use of Community Clinics indicate that bringing services to the proximity of women's home is not adequate to ensure their utilization by community people.

In order to increase the efficiency of the model, UHFWC Management Committees were reactivated in 18 unions so that community monitoring and resource mobilization through active community participation can be ensured. The development of facility-specific "Action Plan" through participatory workshops attended by members of the UHFWC Management Committees, UHFWC service providers, and upazila program managers was critical to improve the 
readiness of the facilities for $24 / 7$ normal delivery services, to create, manage and use the community fund, and to generate demand in the community for UHFWC services.

Qualitative findings reveal that with the existing human resources, UHFWCs are able to provide $24 / 7$ normal delivery service. Program managers reported that family welfare visitors (FWVs) did not face any problems to provide $24 / 7$ normal delivery services along with other services at the UHFWC. Most service providers stated that they have an assistant and the necessary equipment at UHFWCs for providing normal delivery services at night. The introduction of mobile connectivity between FWVs and pregnant women was critical to ensure 24/7 availability of FWVs for delivery services. Service providers experienced an increase in maternal health check-ups and normal deliveries at UHFWCs and attributed these improvements partly to the reactivation of Management Committee towards improving facility readiness and 24-hour availability of normal delivery services and introduction of provider-client phone communication to encourage institutional deliveries.

A key success of the project lies in the regular participation of local government representatives at the monthly meetings of the UHFWC Management Committee as perceived by almost all service providers. Another encouraging aspect of the community mobilization intervention is that it has been able to increase support in the community and collect some funds from the local population for the maintenance and improvement of physical capacity of the UHFWCs. The proportion of contributions to the cost of sustaining the intervention is quite high in some unions. If such contributions can be collected in all unions, it will considerably reduce the amount of funds required from the intervention. Both program managers and service providers highlighted the contribution of the UHFWC Management Committee to the physical improvement of UHFWCs and recommended steps to continue the fund after the project period: local-level advocacy to build ownership among community members for the management of UHFWCs and active role of UHFWC providers to organize monthly meetings of the UHFWC Management Committee on a regular basis.

The project has observed two main weaknesses of the initiative: one is fear and subsequent reluctance of the local government representatives to raise and spend money in the absence of clear-cut policy guidelines from the government. The other weakness is the lack of rigorous and effective monitoring and supervision from the higher authorities. 


\section{Introduction}

In rural areas of Bangladesh, emergency obstetric care $(\mathrm{EmOC})$ services are available at the upazila level and above. There is a comprehensive network of government health facilities that provides maternal health services down to the community level; however, these are not being fully utilized. One-third of the Upazila Health Complexes ${ }^{1}$ (UHCs) have been upgraded to provide EmOC services. Despite the genuine efforts of the government, the impact of this comprehensive health services network has been much less than the expected level, largely because of poor utilization. In rural areas, two-thirds of deliveries occur at home assisted largely by unskilled or traditional birth attendants (64\%) (NIPORT, Mitra and Associates, and ICF International 2016). This means that union-level facilities are not optimally utilized to increase the rate of institutional deliveries.

At the union level, fixed-facility service is provided through the Union Health and Family Welfare Center ${ }^{2}$ (UHFWC). These union-level facilities (UHFWC is used interchangeably) are designed to improve maternal health by making services available to the people in rural areas. UHFWCs remain open six days a week and services are provided from 8:00 am to 2:30 pm as an outdoor service. Leaving UHFWCs as only outdoor service facilities remains as a chief barrier for the rural women to have access to safe delivery services, although these centers have the full potential to provide $24 / 7$ normal delivery services.

At present, the majority of deliveries in rural areas take place at homes with higher risk of morbidity and mortality which is often compounded by the unwillingness of pregnant women to receive maternal health care services from UHC due to the long distance from their home. On the other hand, most of the UHFWCs do not have the provision to provide 24-hour normal delivery services which is in close proximity of most of the women. To achieve the national goal of reducing the maternal mortality ratio, it is crucial to ensure access to institutional delivery in rural areas. Transforming the UHFWC to a round-the-clock facility with additional capacity to provide safe delivery services will benefit pregnant women living in rural areas by reducing the difficulties of traveling a long distance, and providing the comfort in receiving services from the providers they know.

Currently, in Bangladesh there are several programs addressing the common objective of reducing maternal mortality. Very few of these initiatives are directed towards strengthening the union-level government facilities to provide round-the-clock safe delivery services, which is one of the essential steps to reduce maternal mortality and morbidity. Yet, many of the districts were not included to such targeted programs.

In the last sector programs (1998-2011), the Directorate General of Family Planning (DGFP) upgraded approximately 1,500 UHFWCs to provide normal delivery services, but only one-fifth of them are providing limited services. Recently, the DGFP undertook an initiative to provide 24-hour normal delivery services in all upgraded UHFWCs. Nevertheless, providing round-the-clock normal delivery services from union-level health facilities is beset with several infrastructural and managerial problems under the existing government health service delivery system. There are several areas where improvement is required to transform UHFWC from an outdoor center to a first-level maternity clinic, where 24-hour services will be available. It is important to understand the processes needed to provide 24-hour normal delivery services at UHFWCs.

To address this issue, the Population Council, with financial support from UKaid through Crown Agents, under Joint Donor Technical Assistance Fund (JDTAF) of the Ministry of Health and Family Welfare (MOHFW) provided technical assistance to the DGFP to implement an Operations Research (OR) study in 24 UHFWCs in 2 districts that tests the effectiveness of a model to strengthen UHFWCs so that they can provide 24-hour normal delivery services.

${ }^{1}$ Administered by DGHS, Upazila Health Complex is the first-level hospital in rural area that have both inpatient and outpatient facilities. There are 407 Upazila Health Complexes, each covering 300,000 population.

2 In rural areas, DGFP provides maternal health check-ups, limited curative care for children and family planning services at the union level (lowest administrative unit covering 30,000 to 40,000 population) through its 3,900 UHFWCs. 


\section{Project Description}

\section{DESIGN}

This UHFWC OR study used a separate sample pre-test and post-test control design of five groups, including four intervention groups and a control group. Broadly, interventions included: human resource strengthening, community participation, and referral linkage strengthening. Four combinations of three different interventions were tested in the four intervention groups.

- Strategy I: Full Intervention (Human Resource Strengthening, Community Participation, and Referral Linkage Strengthening)

- Strategy II: Human Resource Strengthening with Community Participation

- Strategy III: Human Resource Strengthening with Referral Linkage Strengthening

- Strategy IV: Non-HR Interventions (Community Participation with Referral Linkage Strengthening)

Three of the four intervention strategies experimented with human resource (HR) strengthening in combination with other interventions. In intervention Strategy IV, a combination of community participation and referral linkage strengthening was tested. In the control arm, none of these interventions was implemented (Table 1).

TABLE 2.1 Study design

\begin{tabular}{|c|c|c|c|c|c|c|}
\hline \multirow{2}{*}{\multicolumn{2}{|c|}{ Types of interventions }} & \multicolumn{4}{|c|}{ Intervention Arms } & \multirow[t]{2}{*}{ Control } \\
\hline & & $\mathrm{I}$ & II & III & IV & \\
\hline \multicolumn{7}{|c|}{ Strengthening human resource capacity } \\
\hline ii) & $\begin{array}{l}\text { Promoting teamwork by linking CSBAs with } \\
\text { FWV }\end{array}$ & $\mathrm{Y}$ & Y & $\mathrm{Y}$ & $\mathrm{N}$ & $\mathrm{N}$ \\
\hline iii) & QA visit from upazila level & & & & & \\
\hline \multicolumn{7}{|c|}{ Community participation } \\
\hline i) & Reactivating UHFWCMC & $\mathrm{Y}$ & $\mathrm{Y}$ & $\mathrm{N}$ & Y & $\mathrm{N}$ \\
\hline ii) & Strengthening BCC activities & & & & & \\
\hline \multicolumn{7}{|c|}{ Strengthening referral linkages along with } \\
\hline
\end{tabular}

$\mathrm{Y}=$ Yes. $\mathrm{N}=$ No. $\mathrm{BCC}=$ Behavior Change Communication. CSBA = Community Skilled Birth Attendant. FWV = Family Welfare Visitor. QA = Quality Assurance. UHFWC = Union Health and Family Welfare Center. UHFWCMC $=$ UHFWC Management Committee.

\section{LOCATION}

To ensure broad representativeness from around the country, UHFWCs were selected by using a multi-stage sampling method. The process began with selecting two districts purposively from different parts of Bangladesh, as there was variation in the performance of districts in improving the maternal health situation, which is reflected in the utilization of health services from facilities. Chittagong is one of the largest districts in Bangladesh, consisting of 14 upazilas and 198 unions. Munshiganj district, on the other hand, consists of 6 upazilas and 68 unions. Among the 266 unions in these two districts, UHFWCs are operated by the DGFP in 174 unions. Non-exposure to any significant program activity in maternal health was a key consideration in the selection of these two districts. Four upazilas (other than Sadar) was then selected purposively from each district. From each of the upazilas, UHFWCs that are upgraded with a labor room and a recovery room and have family welfare visitors (FWVs) in place were selected. Three such UHFWCs from each upazila received the interventions.

A total of 24 UHFWCs from eight upazilas in Chittagong and Munshiganj districts were exposed to the interventions. Six UHFWCs from another district ( 2 upazilas from the district and 3 UHWFCs from each of the 2 upazilas) comparable to intervention facilities served the control sites. Interventions were assigned at the upazila level, with two upazilas each getting one of the four strategies. Therefore, six UHFWCs from two upazilas each received one of the four intervention strategies. 


\section{Methodology}

\section{STUDY DESIGN}

To generate evidence for scaling up a model to provide 24-hour normal delivery services at UHFWCs, the OR study was designed to utilize both baseline (pre-intervention) and endline (post-intervention) surveys with married women of reproductive age, which was the key research activity that addressed impact on the demand side. The study collected data using a combination of qualitative and quantitative methods.

\section{DATA COLLECTION}

Strengthening of UHFWCs for providing round-the-clock normal delivery services was a two-year project, which was designed to assess and compare the impact of the interventions on various aspects of maternal health care including trends in program uptake, institutional delivery rates, quality of care, experiences of service providers and users, and program cost. The study collected primary data using a combination of qualitative and quantitative methods at two times with a 12-month interval in between, from 24 intervention and 6 comparison unions of 3 districts in Bangladesh.

Comparisons between before and after the intervention as well as between intervention and control areas enables the project to measure the impact of the interventions. The same instruments were used during the pre- and postintervention assessments. The program evaluation took place primarily at two different levels with specific objectives at each level: union-level facilities, and among recently delivered mothers in the community. Additionally, evaluation of the program at the national or policy level included secondary data from the government and in-depth interviews with program managers.

\section{A. Community level}

To measure the impact of the interventions, data collected through population-based surveys were used.

\section{Pre- and post-intervention surveys}

The community level assessment is comprised of a population-based survey among eligible women. Surveys were carried out before and after intervention to measure the changes in project outcomes. The participants were randomly selected from the list of women who have given birth in the last one year, which is prepared by the government field-level functionaries. Women were interviewed to know about their health-seeking practices during the last pregnancy, particularly the experiences with institutional delivery, accessibility, affordability and utilization of services, and quality of services received from facilities. A total of 3,902 women from 30 study unions (intervention: 24 and control: 6) were interviewed for both pre- and post-intervention surveys.

\section{Sample size}

The OR study intends to increase the rate of institutional delivery at union-level facilities. Currently, a few UHFWCs conduct deliveries occasionally, with a maximum of 5 percent of the normal deliveries of a union being conducted at these facilities. Intervention UHFWCs aimed for conducting another 25 percent of all deliveries of a union. For estimating the sample size, 5 percent of the normal deliveries is assumed as the baseline. Estimated sample size can be calculated by the following formula with 5 percent level of significance, 80 percent power and design effect of 1.5 . 


$$
\mathrm{N}=\frac{\operatorname{deff} \mathrm{x}\left[\mathrm{Z}_{1-\alpha} \sqrt{2 * \mathrm{p}(1-\mathrm{p})}+\mathrm{Z}_{1-\beta} \sqrt{\mathrm{p}_{1}\left(1-\mathrm{p}_{1}\right)+\mathrm{p}_{2}\left(1-\mathrm{p}_{2}\right)}\right]^{2}}{\left(\mathrm{p}_{2}-\mathrm{p}_{1}\right)^{2}}
$$

Where:

$\mathrm{N}=$ Estimated sample size

$Z_{1-\alpha}=$ Value of $Z$ for level of significance alpha (at 0.05 level of significance value of $Z$ is 1.96)

$Z_{1-\beta}=$ Power, which indicates that change did not occur by chance. Value of $Z$ for power $\beta$ (at power level 0.80 , value of $Z_{\beta}$ is 0.84 )

$\mathrm{p}_{1}=$ Current delivery rate at UHFWC. In this calculation we have assumed this value to be approximately $5 \%$, given that there are a limited number of deliveries that are taking place at UHFWCs after the upgradation. The value of $p_{1}$ is thus 0.05

$\mathrm{p}_{2}=$ Expected delivery rate of UHFWC at the end of the intervention activities. Here, we have aimed for it to be $30 \%$; hence the value of $p_{2}$ is 0.3

$\mathrm{p}=\left(\mathrm{p}_{1}+\mathrm{p}_{2}\right) / 2$

Deff $=$ Design effect has been assumed 1.5 due to possible variations across unions

With the above formula and allowing for approximately $10 \%$ non-response, the sample size comes to approximately 62 women for each union. Thus, the sample size is 1,860 for 30 study unions (intervention: 1,488 women in 24 unions and control: 372 women in 6 unions). Systematic random sampling technique was used for selecting households. From every household, one currently married woman of 18-45 years old who had given birth in the last one year was selected as the respondent. Same number of respondents were interviewed in the post-intervention assessment following the same sampling procedure. Data was collected from December 2014 through March 2015 for pre-intervention and from July through August 2016 for post-intervention.

\section{Participatory research for tool development}

Before introducing interventions, Participatory Rural Appraisal (PRA) sessions with married men and Focus Group Discussions (FGDs) with Local Government Institute (LGI) members were conducted. A total of 24 PRA sessions with married men in 24 intervention unions identified issues related to access and availability of normal delivery services at the union level and below, and captured the men's expectations of UHFWCs for delivery services. In addition, 24 FGDs with local government representatives in all intervention unions assessed their perspectives on UHFWC performance, expectations of UHFWCs, and willingness to contribute to infrastructural improvements and facility maintenance. Findings from the PRAs and FGDs helped to develop the guidelines for the functioning of UHFWC Management Committees, and utilization of locally generated funds.

\section{B. Facility level}

The health-facility-level assessment included two types of data collection-provider interviews and facility assessments. Broadly, provider competence and facility readiness were studied.

- Facility assessment. In the pre-intervention phase, at all UHFWCs operated by the DGFP in two intervention districts, facility assessments were conducted to gather information on the characteristics of UHFWCs-human resources, physical facilities, service provision, equipment, drugs and supplies, infection control procedures, and facility management. An Endline assessment was conducted at 24 intervention UHFWCs.

- Provider competence: Pre- and post-intervention surveys were conducted among service providers to assess their maternal health knowledge and capacities and the changes they experienced during the intervention period, and their perceptions of needs at the facility. A total of 51 providers working at the intervention UHFWCs were interviewed for both pre and post surveys. 


\section{Policy level}

- Service statistics: Service statistics and completed management information system (MIS) forms were collected throughout the intervention period from all 30 study UHFWCs. A special MIS form that is tailored to the data needs for targeted analyses on deliveries, developed by Population Council and approved by the DGFP, was administered at all 30 UHFWCs. This MIS form supplements the data from the routine MIS forms available at the facility.

- Cost effectiveness: A cost analysis was carried out to understand economic viability of the program inputs and expected resources to expand the program at the national level. The purpose of the cost analysis is to calculate incremental costs of each program input to assess the feasibility for replicating best strategy. The cost analysis includes only the program costs, that is, the costs of the resources used for implementing the interventions. Research costs for measuring the effect of the interventions is not considered.

- Stakeholder's analysis: There were consultations with key program managers and service providers to understand the implementation of the program as well as the experiences of program utilization. Seventeen indepth interviews were conducted with service providers and program managers ( 8 with union-level providers and 9 with upazila, district, and national level managers) after the implementation of the intervention. In-depth interviews with program managers and service providers allowed exploring their opinions on opportunities and difficulties in providing 24-hour normal delivery services from UHFWCs and eliciting their suggestions for improvement in service delivery. 


\section{Implementation of the Project}

The UHFWC OR study is of 27 months' duration with three distinct phases: pre-intervention, intervention implementation, and evaluation. Preparatory activities were completed in June 2015, and a 12-month intervention period ended in June 2016.

\section{PREPARATORY ACTIVITIES}

\section{Stakeholder orientation and sensitization}

A total of 41 meetings/workshops were conducted to orient and sensitize a wide range of stakeholders and to build an ownership and management support for the program, which include:

- 8 orientation meetings with district, upazila and union level staffs

- 8 orientation meetings with fieldworkers and supervisors

- 7 orientation meetings with UHFWC Management Committees

- 18 Action Plan workshops with service providers and UHFWC Management Committees.

Orientation meetings. With the aim of building ownership and management support for the project, eight orientation meetings with district-, upazila-, and union- level staff were held (one in each intervention upazila). Meetings were attended by government program managers from both health and family planning directorates working at the district and upazila levels, and service providers from the Upazila Health Complex (UHC), UHFWCs, and Community Clinics. In the orientation meetings, project activities were explained and "health" and "family planning" service providers and management staff were sensitized on improving the capacity of UHFWCs in providing 24-hour normal delivery services, monitoring and supervision of UHFWCs, and the importance of a coordinated referral mechanism (from community to upazila/district level). Service providers and management staff of 'health' and 'family planning' were sensitized to work under an integrated referral mechanism.

Orientation meetings with fieldworkers and supervisors. Eight meetings oriented family planning fieldworkers (family welfare assistants, or FWAs) and their supervisors (family planning inspectors, or FPIs) and community health care providers (CHCPs) on the project activities, use and distribution of behavior change communication (BCC) materials, referral of pregnant women, and follow-up of postnatal cases. The coordinated efforts of health and family planning workers in the successful implementation of activities was emphasized in these meetings.

Orientation meetings with the UHFWC Management Committee. UHFWC Management Committees (UHFWCMCs) were reactivated in accordance with the government guideline. In seven upazilas that were exposed to the community mobilization intervention, workshops were organized with members of Management Committees to orient them on project activities, particularly the improved capacity of UHFWCs in providing 24-hour normal delivery services, facility maintenance, community participation, and resource mobilization.

Action Plan workshops. In 18 unions that were exposed to the community mobilization intervention, workshops were held with UHFWCMC members, service providers from UHFWCs, and upazila-level program managers to develop an "action plan" for managing the facility engaging relevant stakeholders. These workshops resulted in the outlining of a specific plan to improve, manage, and monitor UHFWCs towards ensuring round-the-clock normal delivery services. In addition, action plan workshops embarked on the process of mobilizing resources by establishing a "community fund" for UHFWC, with the contribution of Union Parishad, bazaar committees, and community members, for facility maintenance and transportation of referral cases. Key outcomes of the workshops were:

- 18 Action Plans were developed to improve, manage and monitor UHFWCs to ensure round-the-clock normal delivery services. 
- 18 Community Fund was established with the contribution of community people for the maintenance of UHFWC and transportation of referral cases.

\section{DEVELOPMENT OF A PROJECT OPERATIONS GUIDELINE AND COMMUNICATION TOOLS}

For better implementation and management of project activities, a guideline was developed for the UHFWCMCs and the use of funds raised through community participation. Workshops were held at the upazila level to develop this guideline. Additionally, a brochure was developed for distribution among poor pregnant women, community members, and bazaar committees on UHFWC management, community monitoring of UHFWC performance, and utilization of locally generated funds.

To publicize the new status of the UHFWC, a flyer depicting the expected benefits of the project along with a mobile phone number for emergency contact and a sticker containing information on the availability of round-the-clock normal delivery services at the UHFWC were developed and printed for distribution.

\section{IMPLEMENTATION OF INTERVENTIONS}

The Population Council has provided technical assistance to the DGFP to implement intervention activities and has documented the evidence-gathering processes.

\section{Strengthening human resources capacity}

- In 19 out of 24 UHFWCs, FWVs were residential, thus the availability of an FWV for 24-hour normal delivery services was ensured. Phone numbers of UHFWC service providers were publicized across the union through different BCC instruments so that pregnant women could communicate with providers when any need arises.

- The concept of working in a team at the union level was introduced to promote that delivery at a facility is safer than delivery at home. Community skilled birth attendants (CSBAs) were available in one-third of intervention unions and linked with the providers at the UHFWC so that they could refer pregnant women to the UHFWC for normal delivery services.

\section{Increasing community participation}

- UHFWCMCs were reactivated to manage facilities and mobilize resources through active community participation. Monthly meetings were organized to review implementation of interventions and to ensure contributions from the Management Committee.

- A community fund for UHFWC was established to mobilize resources from members of UHFWC Management Committee and the community. UHFWCs had opened bank accounts for the community fund, which were operated by two signatories chosen from the Committee. The Committee used this fund to improve the physical conditions of the UHFWC, conduct emergency maintenance, and subsidize the transportation costs of referral cases. To ensure transparency, fund accumulations, expenditures, and current balances were presented at monthly meetings.

- Activities on promoting awareness and creating demand for facility-based normal delivery services were: interpersonal communication through regular monthly household visits by FWAs, distribution of flyers and brochures, and the placement of signboards and posters in front of the intervention facilities for mass viewing. Along with these, stickers were used to publicize 24-hour normal delivery service as well as associated services.

- UHFWC Management Committees took part in awareness building through courtyard meetings with pregnant mothers, public announcements in the community, and printing and distributing locally-developed leaflets. 


\section{Strengthening referral links}

- A referral mechanism between UHFWCs and higher-level facilities, such as the Upazila Health Complex, Mother and Child Welfare Center, and District Hospital, was strengthened. At the same time, a "referral slip" was introduced for referrals in case of a complicated delivery or one requiring cesarean delivery. At the community level, to follow up on referral cases, FWAs are advised to visit new mothers at their home.

- The project established a transportation networking for referral clients and connectivity between service providers and pregnant women through cell phones. Routinely, FWVs called pregnant women to remind them of recommended care or scheduled visits, contacted higher-level facilities for referrals when needed, and arranged transportation. 


\section{Impact of the Interventions}

\section{KNOWLEDGE ON MATERNAL HEALTH CARE SERVICES}

Table 5.1 shows respondents' knowledge regarding sources of pregnancy care. It is to be mentioned that the background characteristics of the respondents were found almost the same in two surveys (Appendix 1). Private hospital/clinic was the most frequently mentioned source of pregnancy care in intervention and control areas. Prior to the intervention, 76-85 percent of women mentioned about the private facilities in the intervention areas. Chittagong exhibited a large decrease in the proportion of women reporting private facility a source of pregnancy care (Baseline 76\%, Endline 41\%). In Chittagong, UHFWC has emerged as the most popular source of pregnancy care in the past 12 months (75\%). In other intervention district, UHFWC is the second popular source of pregnancy care (Munshiganj: 62\%). Awareness on UHFWC as a source of pregnancy care is much lower in Comilla and it decreased from 62 to 39 percent in the past 12 months.

UHC is another popular source of pregnancy care (Chittagong: $56 \%$, Munshiganj: $53 \%$, Comilla: $43 \%$ ) and women's perception about UHCs increased a little over time in the intervention districts alone. Among others, tertiary hospitals as a source of pregnancy care is widely known to roughly half of the women in Munshiganj and Comilla. The control area (Comilla) witnessed a three-fold increase in the awareness on tertiary hospital (14\% to $44 \%$ ). There was a sharp decrease in the proportion of women having the knowledge on the presence of a qualified doctor's chamber in both Chittagong and Comilla, while it increased in Munshiganj.

TABLE 5.1 Knowledge on sources of pregnancy care in the locality over time (in percent)

\begin{tabular}{lrrrrrr}
\hline Sources of treatment* & \multicolumn{4}{c}{ Intervention } & \multicolumn{3}{c}{ Control } \\
\cline { 2 - 7 } & \multicolumn{3}{c}{ Chittagong } & \multicolumn{2}{c}{ Munshiganj } & \multicolumn{3}{c}{ Comilla } \\
\cline { 2 - 7 } & \multicolumn{1}{c}{ Baseline } & \multicolumn{1}{c}{ Endline } & Baseline & Endline & Baseline & Endline \\
\hline Public facilities & & & & & & \\
$\quad$ Tertiary hospital & 31.4 & 23.3 & 45.1 & 44.2 & 13.9 & 43.9 \\
$\quad$ District hospital & 4.2 & 8.8 & 10.8 & 8.4 & 4.5 & 7.9 \\
MCWC & 12.4 & 18.0 & 2.7 & 2.2 & 2.9 & 1.8 \\
UHC & 47.1 & 55.7 & 51.3 & 53.0 & 44.7 & 43.1 \\
UHFWC & 67.1 & 74.7 & 62.1 & 62.3 & 62.1 & 38.5 \\
$\quad$ Community clinic/Satellite clinic & 28.4 & 29.5 & 19.2 & 26.1 & 58.7 & 31.8 \\
NGO facilities & & & & & & \\
$\quad$ NGO static clinic & 28.1 & 31.2 & 4.2 & 7.1 & 2.6 & 2.3 \\
Private facilities & & & & & & \\
$\quad$ Private hospital/clinic & 76.3 & 40.7 & 85.4 & 73.2 & 69.2 & 88.0 \\
$\quad$ Qualified doctor's chamber & 61.9 & 23.9 & 17.0 & 32.3 & 28.4 & 3.6 \\
N & 783 & 772 & 787 & 790 & 380 & 390 \\
\hline
\end{tabular}

* Multiple responses.

MCWC=Mother and Child Welfare Center. UHC=Upazila Health Complex. UHFWC=Union Health and Family Welfare Center. 
In the pre-intervention period, UHFWCs were widely known as a facility that provides family planning and mother and child care services, followed by general illness services. Prior to the intervention, women in both Chittagong and Munshiganj had little knowledge on 24-hour normal delivery services provided the UHFWCs. Interventions have resulted in improving the awareness of 24-hour delivery service in both areas. At the time of the baseline survey, women in Munshiganj were completely unaware of the availability of 24-hour normal delivery services and only six percent in Chittagong was aware of it. After the intervention, the availability of 24-hour normal delivery services at the UHFWCs is known to more than one-third of the women. Besides, awareness of family planning as well as maternal health check-ups increased but concurrently women's perception about the availability of general illness services has become less intense at the post-intervention period in both districts. The perception about UHFWC services has changed over time, in favor of 24/7 normal delivery services and other maternal health services (Figure $5.1)$.

FIGURE 5.1 Respondent's knowledge regarding services provided at the UHFWC over time (in percent) *

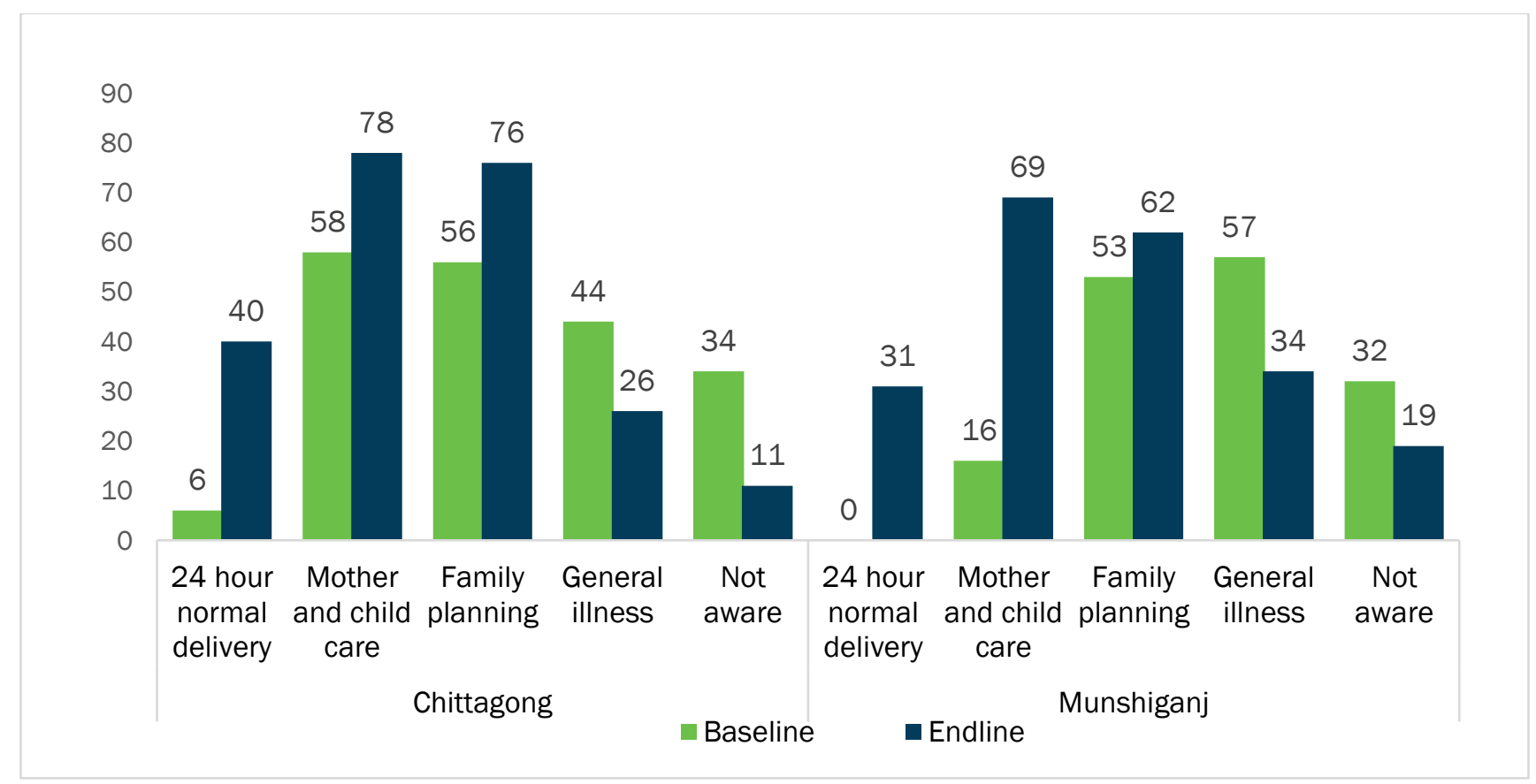

*Multiple responses. 
Respondents were asked about problems women in the community faced on receiving services from UHFWCs. Findings shown in Table 5.2 suggest that 70 percent of the women in Chittagong mentioned that women in the community did not face any problems to receive services from the facility compared to only 34 percent in Comilla. In addition, a large proportion of women were not aware of any problems of community women to receive services from the facility. Community women in Munshiganj were more likely than other two districts to have confronted problems in seeking services from the UHFWC as perceived by the respondents (Munshiganj: 19\%, Chittagong: 6\%, Comilla: $6 \%$.

A big difference exists in the type of problems women in the community faced to receive UHFWC services. More than half of the respondents in Chittagong mentioned that women spend money for receiving services from the UHFWC which is supposed to be cost free while this problem was perceived to be least common in Munshiganj (7\%). "Unavailability of medicine" was mentioned by more than two-thirds of the respondents in Munshiganj and Comilla. Provider attitude and round-the clock availability of providers were not major problems in both intervention and control areas.

TABLE 5.2 Respondent's knowledge regarding problems to receive services from UHFWC by the women in the community (in percent)

\begin{tabular}{|c|c|c|c|c|c|c|}
\hline \multirow[t]{3}{*}{ Problems to receive services } & \multicolumn{4}{|c|}{ Intervention } & \multirow{2}{*}{\multicolumn{2}{|c|}{$\begin{array}{l}\text { Control } \\
\text { Comilla }\end{array}$}} \\
\hline & \multicolumn{2}{|c|}{ Chittagong } & \multicolumn{2}{|c|}{ Munshiganj } & & \\
\hline & Baseline & Endline & Baseline & Endline & Baseline & Endline \\
\hline \multicolumn{7}{|l|}{ Facing problems } \\
\hline Yes & 13.9 & 6.0 & 16.5 & 19.1 & 7.6 & 6.4 \\
\hline No & 38.5 & 69.6 & 32.3 & 40.0 & 47.1 & 33.7 \\
\hline Don't know & 47.6 & 24.4 & 51.2 & 40.9 & 45.3 & 59.9 \\
\hline Total & 100.0 & 100.0 & 100.0 & 100.0 & 100.0 & 100.0 \\
\hline $\mathrm{N}$ & 783 & 767 & 787 & 790 & 380 & 390 \\
\hline \multicolumn{7}{|l|}{ Type of problems* } \\
\hline Spending money for treatment & 56.9 & 63.0 & 26.2 & 7.3 & 20.7 & 36.0 \\
\hline $\begin{array}{l}\text { Round-the clock availability of } \\
\text { providers }\end{array}$ & 24.8 & 10.9 & 20.8 & 29.8 & 6.9 & 28.0 \\
\hline Lack of friendly behavior & 25.7 & 43.5 & 40.0 & 43.7 & 6.9 & 8.0 \\
\hline Unavailability of medicine & 55.1 & 63.0 & 79.2 & 76.8 & 69.0 & 68.0 \\
\hline Inconvenient service hours & 32.1 & 10.9 & 13.1 & 9.9 & 24.1 & 12.0 \\
\hline $\mathrm{N}$ & 109 & 46 & 130 & 151 & 29 & 25 \\
\hline
\end{tabular}

*Multiple responses. 


\section{Knowledge on sources of treatment for delivery complications}

Most women were aware of sources of treatment for life threatening complications. At the time of the baseline survey, in both intervention and control areas, more than 70 percent of women mentioned private hospital/clinic as a source of treatment for delivery complications. Women from intervention districts have become less aware of private facilities as a source of care for complications than those in the control district. Among public-sector facilities, medical college hospital and Upazila Health Complex are widely known as sources of complications management care to women in both intervention districts. UHFWC is another most frequently cited source of treatment for complications. However, a clear intervention-control gap is found between baseline and endline findings - the awareness of public facilities as a source of care for complications increased in both intervention areas whereas the control area witnessed a decrease in the awareness of public facilities except the tertiary hospital. District-level public facilities that are well equipped to treat delivery complications were known to a small proportion of women in both intervention and control areas. For example, around 10 percent of women were aware of District Hospital and MCWC as the source of treatment for complications (Table 5.3).

TABLE 5.3 Knowledge regarding sources of treatment for delivery complications (in percent)

\begin{tabular}{|c|c|c|c|c|c|c|}
\hline \multirow[t]{3}{*}{ Sources of treatment* } & \multicolumn{4}{|c|}{ Intervention } & \multirow{2}{*}{\multicolumn{2}{|c|}{$\begin{array}{l}\text { Control } \\
\text { Comilla }\end{array}$}} \\
\hline & \multicolumn{2}{|c|}{ Chittagong } & \multicolumn{2}{|c|}{ Munshiganj } & & \\
\hline & Baseline & Endline & Baseline & Endline & Baseline & Endline \\
\hline \multicolumn{7}{|l|}{ Public facilities } \\
\hline Tertiary hospital & 33.6 & 39.2 & 60.1 & 62.9 & 18.2 & 45.6 \\
\hline District hospital & 2.9 & 10.0 & 17.1 & 11.7 & 3.2 & 7.5 \\
\hline MCWC & 11.1 & 20.1 & 2.7 & 2.7 & 2.9 & 1.9 \\
\hline UHC & 42.4 & 59.3 & 51.9 & 60.3 & 48.0 & 33.4 \\
\hline UHFWC & 40.5 & 59.0 & 21.1 & 37.3 & 45.9 & 25.1 \\
\hline Community clinic & 9.1 & 11.2 & 2.3 & 6.5 & 17.2 & 8.1 \\
\hline \multicolumn{7}{|l|}{ NGO facilities } \\
\hline NGO static clinic & 18.6 & 21.2 & 2.4 & 1.5 & 1.3 & 0.5 \\
\hline \multicolumn{7}{|l|}{ Private facilities } \\
\hline Private hospital/clinic & 80.9 & 41.3 & 83.2 & 78.1 & 73.4 & 93.8 \\
\hline Qualified doctor's chamber & 47.8 & 20.2 & 11.6 & 14.6 & 15.8 & 3.0 \\
\hline $\mathrm{N}$ & 783 & 697 & 787 & 786 & 380 & 371 \\
\hline
\end{tabular}

*Multiple responses.

MCWC=Mother and Child Welfare Center. UHC=Upazila Health Complex. UHFWC=Union Health and Family Welfare Center. 


\section{UTILIZATION OF ANTENATAL CARE SERVICES}

Seeking antenatal care (ANC) is almost universal in the intervention areas which remained almost the same over time. On the other hand, in the control area it has decreased from 95 to 82 percent in the past 12 months (Table 5.4). The difference between intervention and control is largest when the utilization of higher number of ANC visits is considered. Women in the intervention areas received on an average four check-ups compared to three check-ups in the control area. In Chittagong, one-year intervention period has witnessed an increase of 10 percentage points for four or more ANC visits while the other intervention and control districts experienced a little decrease. At the time of the endline survey, more than two-thirds of women in the intervention areas received at least four ANC compared to 43 percent women in the control area. Between the intervention districts, a large difference in receiving four or more ANC exists (Chittagong: 79\%, Munshiganj: 62\%).

TABLE 5.4 Changes in uptake of antenatal care services (in percent)

\begin{tabular}{|c|c|c|c|c|c|c|}
\hline \multirow[t]{3}{*}{ Utilization of ANC } & \multicolumn{4}{|c|}{ Intervention } & \multirow{2}{*}{\multicolumn{2}{|c|}{$\begin{array}{l}\text { Control } \\
\text { Comilla }\end{array}$}} \\
\hline & \multicolumn{2}{|c|}{ Chittagong } & \multicolumn{2}{|c|}{ Munshiganj } & & \\
\hline & Baseline & Endline & Baseline & Endline & Baseline & Endline \\
\hline Received ANC & 96.9 & 95.7 & 95.3 & 95.6 & 94.7 & 81.8 \\
\hline $\mathrm{N}$ & 783 & 772 & 787 & 790 & 380 & 390 \\
\hline Mean ANC visits & 4.0 & 4.2 & 3.9 & 3.8 & 3.3 & 3.1 \\
\hline \multicolumn{7}{|l|}{ Number of visits } \\
\hline One visit & 5.7 & 3.1 & 8.7 & 5.4 & 14.4 & 17.6 \\
\hline Two visits & 9.5 & 6.0 & 11.5 & 10.9 & 18.6 & 17.2 \\
\hline Three visits & 15.8 & 11.5 & 13.7 & 21.3 & 19.4 & 22.2 \\
\hline Four visits or more & 69.0 & 79.4 & 66.1 & 62.2 & 47.6 & 43.0 \\
\hline Total & 100.0 & 100.0 & 100.0 & 100.0 & 100.0 & 100.0 \\
\hline $\mathrm{N}$ & 759 & 739 & 750 & 755 & 360 & 319 \\
\hline \multicolumn{7}{|c|}{ Reasons for receiving first ANC } \\
\hline For check-up only & 69.7 & 88.6 & 79.6 & 86.4 & 73.9 & 77.1 \\
\hline Because of problem & 8.6 & 9.2 & 4.3 & 3.7 & 9.2 & 10.7 \\
\hline For both reasons & 21.7 & 2.2 & 16.1 & 9.9 & 16.9 & 12.2 \\
\hline Total & 100.0 & 100.0 & 100.0 & 100.0 & 100.0 & 100.0 \\
\hline $\mathrm{N}$ & 759 & 739 & 750 & 755 & 360 & 319 \\
\hline
\end{tabular}

Table 5.4 further presents the key purpose of receiving first ANC. Routine check-ups as the key reason for seeking antenatal care has become more pronounced overtime. More women in the intervention than the control area reported ANC for a normal check-up (Intervention: 89\%, 86\%; Control: 77\%). The proportion of women receiving an ANC because of pregnancy complications was 11 percent in the control area, which is less common in the intervention areas. 
It is customary for women to receive the first ANC from facilities, irrespective of the exposure to the intervention. Women from the intervention districts were less likely to receive ANC from private facilities than women in the control district. In the intervention areas, 40 percent of the women sought antenatal care from the public-sector facilities. An increase in the use of public facilities for check-up was observed for the intervention areas, while the control area did not have any changes. The contribution of NGO facilities to the overall utilization of antenatal care is small (Table 5.5).

TABLE 5.5 Changes in uptake of first antenatal care services by facility (in percent)

\begin{tabular}{|c|c|c|c|c|c|c|}
\hline \multirow[t]{3}{*}{ Utilization of ANC } & \multicolumn{4}{|c|}{$\begin{array}{c}\text { Intervention } \\
\end{array}$} & \multirow{2}{*}{\multicolumn{2}{|c|}{$\begin{array}{l}\text { Control } \\
\text { Comilla } \\
\end{array}$}} \\
\hline & \multicolumn{2}{|c|}{ Chittagong } & \multicolumn{2}{|c|}{ Munshiganj } & & \\
\hline & Baseline & Endline & Baseline & Endline & Baseline & Endline \\
\hline \multicolumn{7}{|l|}{ Place of ANC } \\
\hline Home & 3.3 & 3.7 & 12.3 & 8.3 & 14.4 & 3.4 \\
\hline Facility & 96.7 & 96.3 & 87.7 & 91.7 & 85.6 & 96.6 \\
\hline Total & 100.0 & 100.0 & 100.0 & 100.0 & 100.0 & 100.0 \\
\hline $\mathrm{N}$ & 759 & 739 & 750 & 755 & 360 & 319 \\
\hline \multicolumn{7}{|l|}{ Type of facilities } \\
\hline Public & 34.5 & 39.6 & 38.6 & 44.4 & 30.2 & 31.2 \\
\hline Private & 54.6 & 46.8 & 58.1 & 51.9 & 67.9 & 68.8 \\
\hline NGO & 10.9 & 13.6 & 3.3 & 3.8 & 1.9 & 0.0 \\
\hline Total & 100.0 & 100.0 & 100.0 & 100.0 & 100.0 & 100.0 \\
\hline $\mathrm{N}$ & 734 & 712 & 658 & 692 & 308 & 308 \\
\hline \multicolumn{7}{|l|}{ Public facilities } \\
\hline Tertiary hospital & 2.4 & 1.4 & 11.0 & 7.5 & 6.5 & 5.2 \\
\hline District hospital & 0.8 & 0.4 & 1.2 & 2.3 & 2.2 & 4.2 \\
\hline MCWC & 8.7 & 12.1 & 2.8 & 1.0 & 4.3 & 7.3 \\
\hline UHC & 9.1 & 7.8 & 13.0 & 19.2 & 7.5 & 26.0 \\
\hline UHFWC & 68.0 & 68.1 & 62.2 & 55.7 & 37.6 & 43.8 \\
\hline Community clinic/Satellite clinic & 11.0 & 10.2 & 9.8 & 14.3 & 41.9 & 13.5 \\
\hline Total & 100.0 & 100.0 & 100.0 & 100.0 & 100.0 & 100.0 \\
\hline $\mathrm{N}$ & 253 & 282 & 254 & 307 & 93 & 96 \\
\hline
\end{tabular}

It is the UHFWC which is mainly utilized for ANC in both intervention and control areas. In the intervention areas, twothirds of the women who received ANC from public facilities sought ANC from the UHFWC while it is notably lower at 44 percent in the control area. Between the intervention sites, the UHFWC utilization remained the same in Chittagong but in Munshiganj it decreased by 6 percentage points while in the control site UHFWC utilization increased by 6 percentage points. Among other public facilities, women in the control area were twice as likely to use UHC for ANC as those in the intervention areas (Control: 26\%; Intervention: $8 \%, 19 \%$ ). The use of communitylevel facilities for ANC was extremely low. 
Figure 5.2 illustrates the utilization of first antenatal check-ups by type of providers, e.g., doctor, mid-level providers and unqualified provider. It is almost universal in both intervention and control areas to receive ANC check-ups from medically trained providers (doctor, nurse, paramedic, FWV, and community skilled birth attendant). Among qualified service providers, doctors and mid-level providers (nurse, paramedic and FWV) were mostly consulted for antenatal care. Use of mid-level providers for ANC increased in the intervention areas. Yet, 7-11\% women sought ANC from unqualified providers. The control area has witnessed notable changes with a large increase in the use of doctors (Baseline: 59\%, Endline: 73\%). The decrease in using unqualified providers for ANC services was complemented by a remarkable increase in the use of qualified doctors in the control area.

FIGURE 5.2 Changes in uptake of first antenatal care services by type of provider (in percent)

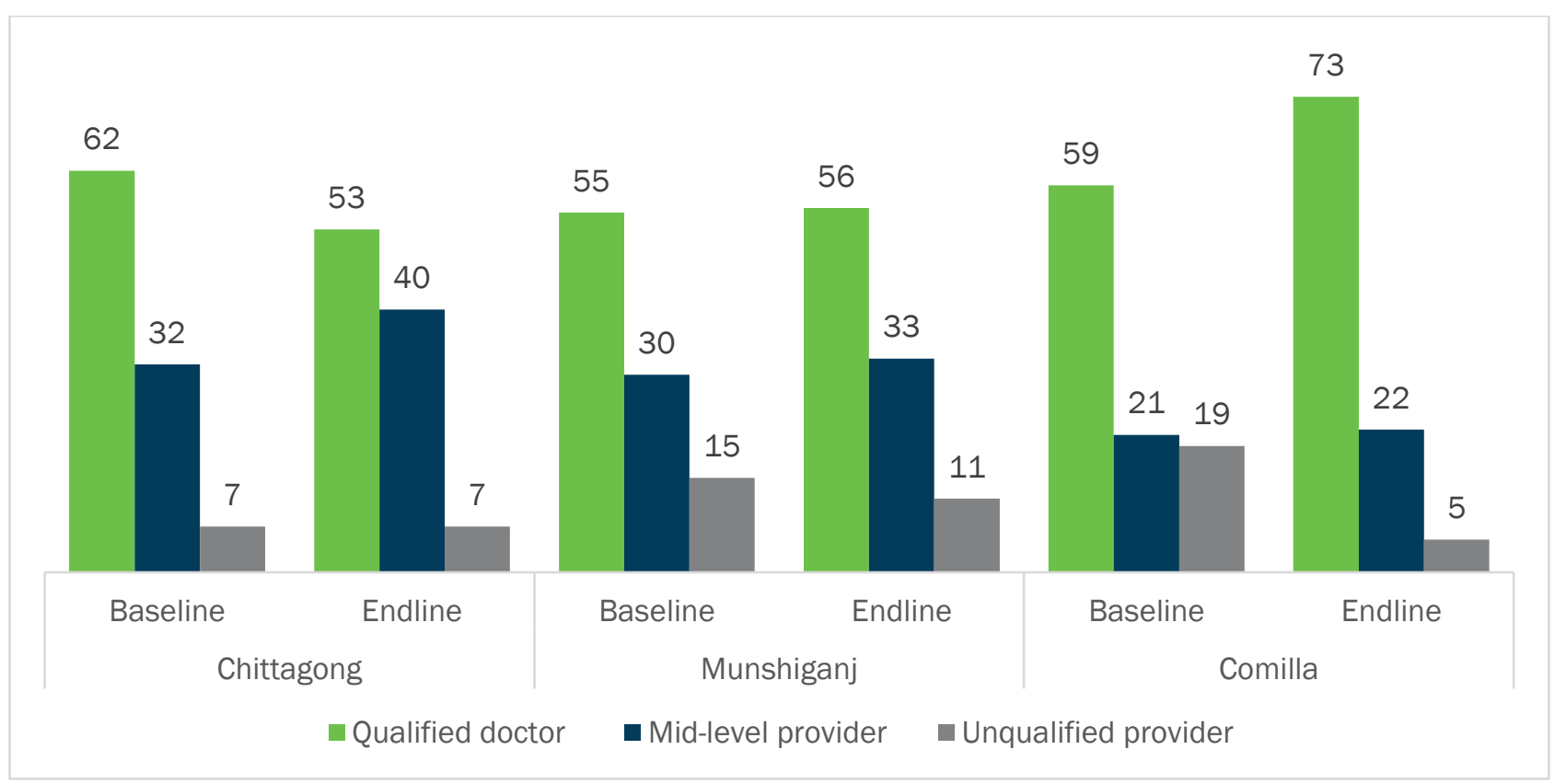




\section{Quality of antenatal care services}

Client perspectives on antenatal check-ups were analyzed to measure the quality of those services, which implies the level of client satisfaction too. A weighted composite quality score was constructed based on a maximum of three processes or aspects: responsiveness, physical examination, and prevention and case management. The composite quality index was constructed using the data collected through the household survey. A total of 16 indicators were used to calculate composite quality score for ANC service (Appendix 2).

For ANC services, responsiveness was measured in terms of whether the provider maintained audio and visual privacy for the client, listened attentively to the client, explained the problem and ensured client's comfort in asking questions. Physical examination included measuring client's height, weight, blood pressure, palpating abdomen for fetal presentation, performing internal examination for vaginal discharge, checking anemia, and prescribing for blood test, urine test and ultrasonogram. Prevention and case management included whether provider advised on nutrition, complications during delivery, referral services if complications occur during delivery, and prescribed and provided medicine.

TABLE 5.6 Quality of care score for antenatal care services (score 0-1)

\begin{tabular}{|c|c|c|c|c|c|c|}
\hline \multirow[t]{3}{*}{ Aspects of care } & \multicolumn{4}{|c|}{ Intervention } & \multirow{2}{*}{\multicolumn{2}{|c|}{$\begin{array}{l}\text { Control } \\
\text { Comilla }\end{array}$}} \\
\hline & \multicolumn{2}{|c|}{ Chittagong } & \multicolumn{2}{|c|}{ Munshiganj } & & \\
\hline & Baseline & Endline & Baseline & Endline & Baseline & Endline \\
\hline Responsiveness & 0.94 & 0.85 & 0.78 & 0.69 & 0.91 & 0.98 \\
\hline Physical examination & 0.58 & 0.50 & 0.57 & 0.56 & 0.54 & 0.39 \\
\hline Prevention and case management & 0.70 & 0.79 & 0.68 & 0.69 & 0.76 & 0.73 \\
\hline Composite score (weighted) & 0.70 & 0.64 & 0.65 & 0.62 & 0.72 & 0.61 \\
\hline $\mathrm{N}$ & 758 & 706 & 750 & 720 & 360 & 315 \\
\hline
\end{tabular}

Regardless of the exposure to interventions, the quality of antenatal care marginally declined over time (Table 5.6). Comparison of composite score on ANC services across the facilities indicates marginally higher quality of ANC services being provided at the intervention facilities compared to control facilities (weighted composite score: intervention 0.64, 0.62, control 0.61). "Responsiveness" earned the highest score among three aspects of care. Provider attitude is worse in Munshiganj, which is reflected in its lowest score on responsiveness $(0.69)$. The score on prevention and case management is highest in Chittagong (0.79) which implies providers in Chittagong were more likely to advice on necessary care and potential risks than in Munshiganj and Comilla. 


\section{UTILIZATION OF DELIVERY SERVICES}

Findings reveal a higher rate of institutional delivery in the intervention districts than in the control district. The rate of institutional delivery increased in both intervention and control sites. In the post-intervention period, 72-79 percent of women deliver at facilities in the intervention areas, while it is much lower in the control area at 53 percent (Table 5.7).

Private facilities have emerged as the main source of institutional delivery, which is widely used in the control area. In the control area 81 percent of the institutional deliveries were conducted at private facilities while in the intervention areas, private facilities conducted about half of the institutional deliveries. The public sector contribution to institutional deliveries increased in Chittagong alone. Munshiganj and Comilla had not experienced any changes over time on this item.

TABLE 5.7 Changes in uptake of delivery services by facility (in percent)

\begin{tabular}{|c|c|c|c|c|c|c|}
\hline \multirow[t]{3}{*}{ Type of facility } & \multicolumn{4}{|c|}{ Intervention } & \multirow{2}{*}{\multicolumn{2}{|c|}{$\begin{array}{l}\text { Control } \\
\text { Comilla }\end{array}$}} \\
\hline & \multicolumn{2}{|c|}{ Chittagong } & \multicolumn{2}{|c|}{ Munshiganj } & & \\
\hline & Baseline & Endline & Baseline & Endline & Baseline & Endline \\
\hline \multicolumn{7}{|l|}{ Place of delivery } \\
\hline Home & 32.0 & 27.6 & 24.6 & 21.4 & 51.3 & 47.2 \\
\hline Facility & 68.0 & 72.4 & 75.4 & 78.6 & 48.7 & 52.8 \\
\hline Total & 100.0 & 100.0 & 100.0 & 100.0 & 100.0 & 100.0 \\
\hline $\mathrm{N}$ & 783 & 772 & 787 & 790 & 380 & 390 \\
\hline \multicolumn{7}{|l|}{ Type of facilities } \\
\hline Public & 43.9 & 47.4 & 30.2 & 29.3 & 18.9 & 18.4 \\
\hline Private & 43.9 & 36.1 & 68.1 & 69.5 & 81.1 & 80.6 \\
\hline NGO & 12.2 & 16.5 & 1.7 & 1.2 & 0.0 & 1.0 \\
\hline Total & 100.0 & 100.0 & 100.0 & 100.0 & 100.0 & 100.0 \\
\hline $\mathrm{N}$ & 533 & 559 & 593 & 621 & 185 & 206 \\
\hline \multicolumn{7}{|l|}{ Public facilities } \\
\hline Tertiary hospital & 40.2 & 19.2 & 70.3 & 64.1 & 48.6 & 26.3 \\
\hline District hospital & 3.4 & 8.2 & 2.2 & 6.6 & 11.4 & 13.2 \\
\hline UHC & 12.8 & 17.6 & 9.6 & 12.2 & 20.0 & 34.2 \\
\hline MCWC & 18.8 & 21.7 & 7.8 & 3.3 & 5.7 & 15.8 \\
\hline UHFWC & 24.4 & 33.3 & 10.1 & 13.8 & 14.3 & 10.5 \\
\hline Community clinic & 0.4 & 0.0 & 0.0 & 0.0 & 0.0 & 0.0 \\
\hline Total & 100.0 & 100.0 & 100.0 & 100.0 & 100.0 & 100.0 \\
\hline $\mathrm{N}$ & 234 & 267 & 179 & 181 & 35 & 38 \\
\hline
\end{tabular}

At the time of baseline survey, among public facilities, tertiary hospitals were intensely used for delivery services, and the use of tertiary facilities decreased in all areas over time. Yet, two-thirds of women who delivered at any public facility chose the tertiary hospital for delivery services in Munshiganj. The use of such facilities is lowest in Chittagong (19\%). Overall, the decrease in the use of tertiary hospitals was complemented by increased use of UHCs, MCWCs, and UHFWCs. It is encouraging to note that in the intervention areas one-fourth of the public facilities' deliveries are conducted at the UHFWCs, which is more than twice the rate in control UHFWCs. Chittagong is credited for the largest increase in the UHFWC contribution to institutional deliveries (from $24 \%$ to $33 \%$ ) while it decreased 4 percentage points in the control area. The project had limited impact in increasing the use of UHFWCs in other intervention area, Munshiganj (i.e., an increase from $10 \%$ to $14 \%$ ). 


\section{Delivery services by type and provider}

Findings reveal an inconsistent pattern in the outcome of deliveries. A stark difference exists between two intervention districts in terms of types of delivery. Women in Chittagong were more likely to undergo normal deliveries, while cesarean deliveries were more widespread in Munshiganj (Table 5.8).

The rate of cesarean delivery was extremely high at 58 percent in Munshiganj compared with 38 percent in Comilla. On the other hand, normal deliveries were much higher in Chittagong than two other districts (Chittagong: $77 \%$, Munshiganj: $42 \%$ and Comilla: 62\%). Currently, three-quarters of the births are attended by skilled providers in the intervention areas, which was higher than the control area (63\%). Yet, the proportion of deliveries conducted by the unqualified providers was still high (37\%) in the control area. Among medically trained providers, doctors were mostly used for delivery services across the areas.

TABLE 5.8 Changes in uptake of delivery services by type and provider (in percent)

\begin{tabular}{|c|c|c|c|c|c|c|}
\hline \multirow[t]{3}{*}{ Utilization of delivery services } & \multicolumn{4}{|c|}{ Intervention } & \multirow{2}{*}{\multicolumn{2}{|c|}{$\begin{array}{l}\text { Control } \\
\text { Comilla }\end{array}$}} \\
\hline & \multicolumn{2}{|c|}{ Chittagong } & \multicolumn{2}{|c|}{ Munshiganj } & & \\
\hline & Baseline & Endline & Baseline & Endline & Baseline & Endline \\
\hline \multicolumn{7}{|l|}{ Types of delivery } \\
\hline Normal delivery & 78.3 & 76.6 & 44.2 & 42.2 & 64.2 & 62.3 \\
\hline Cesarean delivery & 21.1 & 23.4 & 55.8 & 57.8 & 35.8 & 37.7 \\
\hline Total & 100.0 & 100.0 & 100.0 & 100.0 & 100.0 & 100.0 \\
\hline $\mathrm{N}$ & 783 & 772 & 787 & 790 & 380 & 390 \\
\hline Medically trained provider & 71.2 & 75.8 & 78.4 & 81.8 & 55.3 & 62.8 \\
\hline Qualified doctor & 42.0 & 40.8 & 64.6 & 64.7 & 40.8 & 43.3 \\
\hline Mid-level provider* & 28.7 & 33.7 & 13.7 & 16.8 & 12.6 & 18.2 \\
\hline Community skilled birth attendant & 0.5 & 1.3 & 0.0 & 0.3 & 1.8 & 1.3 \\
\hline Unqualified provider & 28.8 & 24.2 & 21.6 & 18.2 & 44.7 & 37.2 \\
\hline Total & 100.0 & 100.0 & 100.0 & 100.0 & 100.0 & 100.0 \\
\hline $\mathrm{N}$ & 783 & 772 & 787 & 790 & 380 & 390 \\
\hline
\end{tabular}




\section{Complications management care}

Information on the utilization of delivery complications care is presented in Table 5.9. Prior to the interventions, half of the pregnant women experienced some complications while giving birth. The proportion of women experiencing complications decreased to 33 percent or less in the intervention areas while it remained the same at 49 percent over time in the control area. Almost all women (over 90\%) in both intervention and control areas reported receiving services for delivery complications.

Women, who consulted providers for complications, were asked about the place for treatment. A widespread use of private facilities for delivery complications is reported regardless of the exposure to the intervention. In the intervention areas, 45-70 percent of women mentioned that they sought care at the private hospital/clinic and 2445 percent visited a public facility to manage their complications. It is noticed that the use of private facilities increased in all study areas over time. A remarkable change in the practice of receiving complications management care at home was observed in both intervention and control areas. Chittagong is credited for the largest decrease in seeking care at home from 20 to 6 percent (Table 5.9).

TABLE 5.9 Changes in uptake of delivery complications management care by sources of treatment (in percent)

\begin{tabular}{|c|c|c|c|c|c|c|}
\hline \multirow{3}{*}{$\begin{array}{l}\text { Utilization of delivery complications } \\
\text { care }\end{array}$} & \multicolumn{4}{|c|}{ Intervention } & \multirow{2}{*}{\multicolumn{2}{|c|}{$\begin{array}{l}\text { Control } \\
\text { Comilla }\end{array}$}} \\
\hline & \multicolumn{2}{|c|}{ Chittagong } & \multicolumn{2}{|c|}{ Munshiganj } & & \\
\hline & Baseline & Endline & Baseline & Endline & Baseline & Endline \\
\hline Complications during delivery & 58.2 & 23.3 & 48.3 & 33.4 & 48.9 & 48.9 \\
\hline $\mathrm{N}$ & 783 & 772 & 787 & 790 & 380 & 390 \\
\hline Received service for complications & 96.9 & 90.6 & 97.1 & 96.3 & 97.8 & 92.3 \\
\hline $\mathrm{N}$ & 456 & 192 & 380 & 270 & 186 & 194 \\
\hline \multicolumn{7}{|l|}{ Places of service* } \\
\hline Home & 20.4 & 5.7 & 6.8 & 4.9 & 23.1 & 14.5 \\
\hline Public & 34.2 & 45.1 & 25.7 & 23.9 & 14.8 & 14.0 \\
\hline Private & 38.5 & 45.1 & 66.4 & 70.3 & 61.5 & 75.4 \\
\hline NGO & 7.0 & 10.3 & 1.4 & 0.8 & 0.5 & 0.6 \\
\hline $\mathrm{N}$ & 442 & 170 & 369 & 257 & 182 & 177 \\
\hline
\end{tabular}

* Multiple responses. 


\section{Referral for complications management care}

It is evident from Table 5.10 that a small number of women were referred to another health facility for complications management care. There were more referrals in the intervention areas than in the control area, and the proportion of referrals increased in both intervention areas (from $7 \%$ to $12 \%$ in Chittagong and $3 \%$ to $5 \%$ in Munshiganj) while it decreased in the control area (3\% to $2 \%$ ).

Currently, public and private facilities are almost equally used in the intervention areas for referral. The use of public facilities increased in Munshiganj from 18 to 47 percent over the time, i.e., half of the referral cases were managed by the public facilities, while the situation in Comilla is the opposite (public: $25 \%$, private: $75 \%$ ).

TABLE 5.10 Referral places from where delivery complications care received (in percent)

\begin{tabular}{|c|c|c|c|c|c|c|}
\hline \multirow[t]{3}{*}{ Utilization of referral services } & \multicolumn{4}{|c|}{ Intervention } & \multirow{2}{*}{\multicolumn{2}{|c|}{$\begin{array}{l}\text { Control } \\
\text { Comilla }\end{array}$}} \\
\hline & \multicolumn{2}{|c|}{ Chittagong } & \multicolumn{2}{|c|}{ Munshiganj } & & \\
\hline & Baseline & Endline & Baseline & Endline & Baseline & Endline \\
\hline Referred from first service center & 6.6 & 11.8 & 3.0 & 5.4 & 2.8 & 2.3 \\
\hline $\begin{array}{l}\mathrm{N} \\
\text { Referral places* }\end{array}$ & 442 & 170 & 369 & 257 & 182 & 177 \\
\hline Public facility & 58.6 & 54.6 & 18.2 & 46.7 & 40.0 & 25.0 \\
\hline Medical college hospital & 48.3 & 22.7 & 18.2 & 46.7 & 40.0 & 25.0 \\
\hline District hospital & 10.3 & 22.7 & - & - & - & - \\
\hline MCWC & - & 9.2 & - & - & - & - \\
\hline NGO static clinic & - & 4.5 & 9.1 & - & - & - \\
\hline Private hospital/clinic & 41.4 & 40.9 & 72.7 & 53.3 & 60.0 & 75.0 \\
\hline $\mathrm{N}$ & 29 & 20 & 11 & 14 & 5 & 4 \\
\hline Received service at referral faciliti & & & & & & \\
\hline Yes & 96.6 & 90.9 & 100.0 & 93.3 & 100.0 & 100.0 \\
\hline No & 3.4 & 9.1 & 0.0 & 6.7 & 0.0 & 0.0 \\
\hline Total & 100.0 & 100.0 & 100.0 & 100.0 & 100.0 & 100.0 \\
\hline $\mathrm{N}$ & 29 & 20 & 11 & 14 & 5 & 4 \\
\hline
\end{tabular}

Even after being referred, nine percent of women in Chittagong and seven percent in Munshiganj did not receive any treatment at the referral facilities, but in the control area all women received treatment at referral facilities. 


\section{Out-of-pocket cost of delivery services}

Table 5.11 shows the out-of-pocket (OOP) cost for normal and cesarean deliveries performed at public and private facilities. This report considers an OOP cost defined as a direct cash payment by the individual or household for a health service at the time the service is received. Expenses included for receiving delivery services are: admission fees, consultation fees, laboratory charges, drug costs, transportation cost, unofficial payment for expediting services, and attendant expenditures for staying at the facility.

Women spent almost twice at private facilities than in public facilities for normal delivery service in both intervention (public: BDT 4,991, 4,553; private: BDT 9,051, 8,794) and control areas (public: BDT 4,904; private: BDT 9,140). Changes in the amount of expenditure within sites over time are not large. For private facilities, expenditure increased a little in the intervention areas but decreased in the control area.

The expenditure reported for cesarean deliveries is more than three times the expenditure reported for normal deliveries. Women in Chittagong spent more than the other two districts for cesarean deliveries at both public and private facilities. Moreover, the public-private cost gap for cesarean deliveries is lowest in Chittagong. Women in Munshiganj who had cesarean deliveries at public facilities spent nearly half the amount spent for private facilities (BDT 12,772 vs. BDT 23,485). A similar expenditure pattern is noticed in Comilla (Table 5.11).

TABLE 5.11 Changes in average expenditure pattern for facility-based delivery services by facility type (in Bangladesh Taka)

\begin{tabular}{|c|c|c|c|c|c|c|}
\hline \multirow[t]{3}{*}{ Delivery type } & \multicolumn{4}{|c|}{ Intervention } & \multirow{2}{*}{\multicolumn{2}{|c|}{$\begin{array}{l}\text { Control } \\
\text { Comilla }\end{array}$}} \\
\hline & \multicolumn{2}{|c|}{ Chittagong } & \multicolumn{2}{|c|}{ Munshiganj } & & \\
\hline & Baseline & Endline & Baseline & Endline & Baseline & Endline \\
\hline \multicolumn{7}{|c|}{ Normal delivery } \\
\hline Public & 5,354 & 4,991 & 4,063 & 4,553 & 4,644 & 4,904 \\
\hline Private & 8,076 & 9,051 & 7,895 & 8,794 & 10,140 & 9,140 \\
\hline $\mathrm{N}$ & 244 & 250 & 136 & 142 & 48 & 54 \\
\hline \multicolumn{7}{|c|}{ Cesarean delivery } \\
\hline Public & 22,156 & 24,917 & 10,047 & 12,772 & 12,459 & 11,500 \\
\hline Private & 28,745 & 31,018 & 22,189 & 23,485 & 24,277 & 21,191 \\
\hline $\mathrm{N}$ & 137 & 143 & 413 & 428 & 137 & 138 \\
\hline
\end{tabular}

Note $=$ Approximate exchange rates at the time of reporting were the following: 1 UKE $=98$ BDT 1 US $\$=78$ BDT. 
No major change is observed in the expenditure pattern for receiving normal delivery services across the areas over time. Women who spent BDT 3,001-5,000 is the largest group of who had normal deliveries at public facilities (Intervention: 28\%, 29\%; Control: 42\%), while at private facilities most women spent BDT 5,001-10,000. A maximum of six percent of women spent over BDT 10,000 at public facilities in Chittagong, while one-quarter reported spending over BDT 10,000 for normal delivery services at private facilities with no major district-wise difference. In intervention districts, one in every five women spent only BDT 2,000 or less for normal deliveries at public facilities while less than five percent reported this level of expenditure in the case of private facilities (Table 5.12).

TABLE 5.12 Changes in average expenditure pattern for normal delivery services (in percent)

\begin{tabular}{|c|c|c|c|c|c|c|}
\hline \multirow[t]{3}{*}{ Cost indicator } & \multicolumn{4}{|c|}{ Intervention } & \multirow{2}{*}{\multicolumn{2}{|c|}{$\begin{array}{l}\text { Control } \\
\text { Comilla }\end{array}$}} \\
\hline & \multicolumn{2}{|c|}{ Chittagong } & \multicolumn{2}{|c|}{ Munshiganj } & & \\
\hline & Baseline & Endline & Baseline & Endline & Baseline & Endline \\
\hline \multicolumn{7}{|l|}{ Public } \\
\hline Up to Taka 2,000 & 18 & 18 & 24 & 24 & 12 & 13 \\
\hline Taka 2,001-3,000 & 17 & 19 & 17 & 21 & 12 & 12 \\
\hline Taka 3,001-5,000 & 33 & 29 & 38 & 28 & 47 & 42 \\
\hline Taka 5,001-10,000 & 25 & 28 & 21 & 25 & 29 & 33 \\
\hline Taka>10,000 & 7 & 6 & 0 & 2 & 0 & 0 \\
\hline $\mathrm{N}$ & 134 & 169 & 95 & 92 & 17 & 24 \\
\hline \multicolumn{7}{|l|}{ Private } \\
\hline Up to Taka 2,000 & 2 & 1 & 5 & 6 & 3 & 6 \\
\hline Taka 2,001-3,000 & 5 & 4 & 5 & 8 & 0 & 0 \\
\hline Taka 3,001-5,000 & 27 & 11 & 32 & 10 & 6 & 27 \\
\hline Taka 5,001-10,000 & 42 & 58 & 36 & 50 & 52 & 37 \\
\hline Taka>10,000 & 24 & 26 & 22 & 26 & 39 & 30 \\
\hline $\mathrm{N}$ & 110 & 81 & 41 & 50 & 31 & 30 \\
\hline
\end{tabular}


For receiving cesarean delivery services, the proportion of women spending BDT 10,001-20,000 was the largest group in Munshiganj and Comilla regardless of the types of facilities (e.g., public or private), while in Chittagong women who spent BDT 20,001-30,000 comprised the largest group for both public and private facilities. The expenditure pattern for public facilities reveals a large increase in the proportion of women spending Tk. 10,00120,000 in Munshiganj and Comilla. The proportion of women spending under BDT 10,000 decreased in all three districts.

Out-of-pocket cost for receiving cesarean deliveries is much higher in Chittagong. For example, in Chittagong, 26 percent of women incurred a cost over BDT 30,000 at public facilities and 42 percent at private facilities. Receiving cesarean deliveries at private facilities tends to become costlier over time in intervention districts. Women who spent over BDT 30,000 at private facilities increased remarkably in both intervention districts while the control district exhibits an opposite trend (Table 5.13).

TABLE 5.13 Changes in average expenditure pattern for cesarean delivery services (in percent)

\begin{tabular}{|c|c|c|c|c|c|c|}
\hline \multirow[t]{3}{*}{ Cost indicator } & \multicolumn{4}{|c|}{ Intervention } & \multirow{2}{*}{\multicolumn{2}{|c|}{$\begin{array}{l}\text { Control } \\
\text { amilla }\end{array}$}} \\
\hline & \multicolumn{2}{|c|}{ Chittagong } & \multicolumn{2}{|c|}{ Munshiganj } & & \\
\hline & Baseline & Endline & Baseline & Endline & Baseline & Endline \\
\hline \multicolumn{7}{|l|}{ Public } \\
\hline Taka $<5,000$ & 2 & 2 & 18 & 7 & 0 & 20 \\
\hline Taka 5,001-10,000 & 15 & 8 & 54 & 40 & 39 & 10 \\
\hline Taka 10,001-20,000 & 32 & 31 & 22 & 45 & 56 & 70 \\
\hline Taka 20,001-30,000 & 34 & 33 & 4 & 8 & 5 & 0 \\
\hline Taka >30,000 & 17 & 26 & 2 & 0 & 0 & 0 \\
\hline $\mathrm{N}$ & 47 & 51 & 72 & 75 & 18 & 10 \\
\hline \multicolumn{7}{|l|}{ Private } \\
\hline Taka $<5,000$ & 0 & 2 & 0 & 1 & 0 & 1 \\
\hline Taka 5,001-10,000 & 3 & 1 & 1 & 1 & 2 & 4 \\
\hline Taka 10,001-20,000 & 16 & 11 & 55 & 46 & 34 & 61 \\
\hline Taka 20,001-30,000 & 53 & 44 & 36 & 38 & 52 & 27 \\
\hline Taka >30,000 & 28 & 42 & 8 & 14 & 12 & 7 \\
\hline $\mathrm{N}$ & 90 & 92 & 341 & 353 & 118 & 128 \\
\hline
\end{tabular}




\section{Equity in the access to delivery services}

Equity in the access to maternal health services can be understood from an interaction between economic status and utilization of services. As a measure of economic status a wealth index was calculated for all 3,902 households of the survey. A wealth index has several advantages. It represents a more permanent status than does either income or consumption. A wealth index is more easily measured (with only a single respondent needed in most cases) and requires far fewer questions than either consumption expenditures or income (Rutstein and Johnson 2004).

The wealth index was constructed using household asset data and principal components analysis (SPSS module). Asset information was collected in the household questionnaire, which covers information on household ownership of a number of consumer items ranging from a mobile phone and television to a bicycle or boat, as well as dwelling characteristics like building materials and land ownership. Each asset was assigned a weight (factor score) generated through principal component analysis, and the resulting asset scores were standardized in relation to a standard normal distribution with a mean of zero and standard deviation of one (Watkin et al. 2000). Each household was then assigned a score for each asset, and the scores were summed for each household. Individuals were ranked according to the total score of the household in which they resided. The sample was then divided into five quintiles from one (lowest) to five (highest). Households in the lowest quintile represent the poorest financial situation, whereas households in the highest quintile are regarded as richest. The ratio of lowest to highest quintile was used in estimating the changes in equity. Equity ratio equal to "1" means no differences between poorest and richest wealth groups. Any ratio over " 1 " indicates the greater likelihood of poorest wealth group over the richest wealth group while ratio less than "1" suggests the richest wealth group overpowering the poorest wealth group.

Results presented in Table 5.14 demonstrate that wealth is associated with the utilization of delivery care from facilities $(E R<1)$. The poorest women in intervention area are more likely to receive care at home, which can be explained by the higher equity ratio $(E R>1)$. The rich-poor gap in taking delivery care at home has decreased over time, yet it is more pronounced in Munshiganj than two other districts. In Munshiganj, women from the poorest wealth group is almost three times as likely to deliver at home as their counterpart from the richest wealth group ( $E R=2.75)$, which may be due to the fact that poor women were not aware of UHFWC's 24-hour normal delivery services.

Likewise, wealth has a noticeable impact on the utilization of public facilities for delivery care in the intervention districts as equity ratio increased during the intervention period, indicating higher likelihood of women in the poorest wealth groups to seek free services from public facilities. The pro-poor utilization of public facilities is much higher in Munshiganj district ( $E R=3.65$ ) than two other districts (Chittagong: $E R=2.16$, Comilla: $E R=1.59$ ). 
TABLE 5.14 Equity Ratio in uptake of delivery services over time

\begin{tabular}{|c|c|c|c|c|c|c|}
\hline \multirow[t]{3}{*}{ Utilization of delivery services } & \multicolumn{4}{|c|}{ Intervention } & \multirow{2}{*}{\multicolumn{2}{|c|}{$\begin{array}{l}\text { Control } \\
\text { Comilla }\end{array}$}} \\
\hline & \multicolumn{2}{|c|}{ Chittagong } & \multicolumn{2}{|c|}{ Munshiganj } & & \\
\hline & Baseline & Endline & Baseline & Endline & Baseline & Endline \\
\hline \multicolumn{7}{|l|}{ Place of delivery } \\
\hline Home & 3.73 & 2.54 & 5.45 & 2.75 & 1.94 & 2.07 \\
\hline Facility & 0.56 & 0.66 & 0.61 & 0.77 & 0.45 & 0.45 \\
\hline $\mathrm{N}$ & 783 & 772 & 787 & 790 & 380 & 390 \\
\hline \multicolumn{7}{|l|}{ Type of facilities } \\
\hline Public & 1.45 & 2.16 & 3.14 & 3.65 & 1.93 & 1.59 \\
\hline Private & 0.61 & 0.28 & 0.58 & 0.70 & 0.82 & 0.92 \\
\hline NGO & 1.41 & 1.32 & 1.58 & 0.48 & - & 0.00 \\
\hline $\mathrm{N}$ & 533 & 559 & 593 & 621 & 185 & 206 \\
\hline \multicolumn{7}{|l|}{ Type of delivery } \\
\hline Normal & 1.18 & 1.34 & 2.63 & 2.09 & 1.56 & 1.51 \\
\hline Cesarean & 0.58 & 0.37 & 0.44 & 0.63 & 0.35 & 0.46 \\
\hline $\mathrm{N}$ & 783 & 772 & 787 & 790 & 380 & 390 \\
\hline \multicolumn{7}{|l|}{ Delivery conducted by provider } \\
\hline Qualified doctor & 0.46 & 0.49 & 0.51 & 0.63 & 0.40 & 0.36 \\
\hline Mid-level provider* & 0.75 & 1.03 & 1.93 & 2.50 & 0.84 & 0.89 \\
\hline Unqualified provider & 5.02 & 2.63 & 6.02 & 2.73 & 2.21 & 2.73 \\
\hline $\mathrm{N}$ & 783 & 772 & 787 & 790 & 380 & 390 \\
\hline
\end{tabular}

* Nurse, paramedic, and family welfare visitor.

There has been greater likelihood among women in the poorest households in receiving normal deliveries than women in the richest households ( $E R>1$ ). Conversely, being in the lowest wealth group decreases the likelihood to have sought cesarean deliveries as reflected in equity ratio $(E R<1)$, without any marked difference between intervention and control, which testifies the affordability of rich women to undergo cesarean deliveries, regardless of the emergencies.

Equity in the utilization of skilled delivery care is strongly associated with wealth as women in the poorest wealth group are less likely to seek care from doctors (Chittagong: ER 0.49, Munshiganj: ER 0.63, Comilla: ER=0.36). Equity ratio does not vary over time in seeking delivery care from medically trained providers, both in intervention and control areas. Conversely, receiving delivery care from unqualified providers was much more common among women in the poorest households than their counterpart in the richest households (Chittagong: ER 2.63, Munshiganj: ER 2.73, Comilla: ER=2.73). Poor women, who are in most need, cannot afford to consult qualified providers, which puts them at a risk of morbidity. The most important finding is that the 12-month intervention has witnessed a shift from pro-rich (ER<1) to pro-poor $(E R>1)$ utilization of mid-level providers for delivery services in both intervention districts-an encouraging note for program managers to pay attention on higher use of midlevel providers for reducing the use of unqualified providers by poor women. 


\section{Client perspective on the quality of delivery services}

The composite quality score on delivery services in intervention districts reveals higher client satisfaction with private facilities than with public facilities (Table 5.15). It is estimated that public facilities achieved a score between 0.66 and 0.76 out of 1.00 which is marginally lower than private facilities $(0.75-0.80)$. For each of the processes or aspects of care, no notable variation is observed between public and private facilities. Among the three aspects, "responsiveness" earned the highest score while "level of service" the lowest. Indicators used to measure the quality score are not related to the clinical quality of services (Appendix 3). Hence, a high score suggests good counseling skills and management practices in the facilities.

TABLE 5.15 Quality of care score for delivery services at public and private facilities (score 0-1)

\begin{tabular}{lrrrrrrr}
\hline Aspects of care & \multicolumn{4}{c}{ Intervention } & \multicolumn{2}{c}{ Control } \\
\cline { 2 - 7 } & \multicolumn{3}{c}{ Chittagong } & \multicolumn{2}{c}{ Munshiganj } & \multicolumn{3}{c}{ Comilla } \\
\cline { 2 - 7 } & Baseline & Endline & Baseline & Endline & Baseline & Endline \\
\hline Public facilities & & & & & & & \\
$\quad$ Responsiveness & 0.82 & 0.78 & 0.73 & 0.57 & 0.82 & $0 . .66$ \\
$\quad$ Prevention and case management & 0.75 & 0.79 & 0.63 & 0.66 & 0.62 & 0.76 \\
$\quad$ Level of services & 0.55 & 0.69 & 0.74 & 0.78 & 0.66 & 0.62 \\
Composite score (weighted) & 0.71 & 0.76 & 0.69 & 0.66 & 0.69 & 0.69 \\
$\quad$ N & 234 & 265 & 160 & 148 & 35 & 38 \\
Private facilities & & & & & & \\
$\quad$ Responsiveness & 0.89 & 0.84 & 0.82 & 0.70 & 0.83 & 0.73 \\
$\quad$ Prevention and case management & 0.78 & 0.83 & 0.70 & 0.78 & 0.57 & 0.78 \\
$\quad$ Level of services & 0.70 & 0.72 & 0.67 & 0.76 & 0.65 & 0.70 \\
Composite score (weighted) & 0.79 & 0.80 & 0.73 & 0.75 & 0.67 & 0.74 \\
$\quad$ N & 234 & 202 & 404 & 432 & 150 & 166 \\
\hline
\end{tabular}

Comparison of quality scores for public facilities reveals the lowest quality score for Munshiganj (0.66), which indicates lapses on providing advices and preventive services. The score is higher in Chittagong (0.76). Yet, the composite score achieved by intervention districts is well below the optimum level. A score of 0.80 out of 1.00 is arbitrarily set as an "optimum score" after assessing the necessity of individual indicators in offering the specified service. For all three aspects of care, the achieved score at the public facilities is below the optimum score of 0.80 . In contrast, out of all three aspects of care, private facilities in Chittagong earned an optimum score on "responsiveness" and "prevention and case management". Overall, a low quality score demonstrates the management weaknesses in improving the quality of services. Women living in intervention areas of Chittagong experienced some improvement in quality of services at public facilities while private facilities in Comilla were able to improve services. Overall, improvement in quality of services over time was negligible at both public and private facilities. 


\section{UTILIZATION OF POSTNATAL CARE SERVICES}

Seeking first PNC increased substantially over time; in the intervention areas 75 percent of women or more utilized the services and it is lower at 54 percent in the control area (Table 5.16). A significant improvement occurred in receiving PNC within 48 hours of child birth. Three in every four PNC seekers (Chittagong: 75\%; Munshiganj: 82\%; Comilla: $77 \%$ ) received the service within the first two days of delivery. The improvement in the utilization of postnatal care within two days after birth is encouraging which indicates that provider utilized the opportunity to perform postnatal check-ups immediately after birth. It is also encouraging to note that less than 10 percent of women reported receiving PNC after one week of birth. Improvements are more widespread in the intervention areas.

Findings from Table 5.16 also suggest that irrespective of the intervention exposure, the proportion of women receiving PNC for normal check-up increased (Intervention: $60-84 \%$ and $86-95 \%$, Control: $80-88 \%$ ). The use of PNC for complications is less common in both intervention and control areas. Using PNC for complications is lowest in Munshiganj (5\%).

TABLE 5.16 Changes in uptake of first postnatal care services (in percent)

\begin{tabular}{|c|c|c|c|c|c|c|}
\hline \multirow[t]{3}{*}{ Utilization of PNC } & \multicolumn{4}{|c|}{ Intervention } & \multirow{2}{*}{\multicolumn{2}{|c|}{$\begin{array}{l}\text { Control } \\
\text { Comilla }\end{array}$}} \\
\hline & \multicolumn{2}{|c|}{ Chittagong } & \multicolumn{2}{|c|}{ Munshiganj } & & \\
\hline & Baseline & Endline & Baseline & Endline & Baseline & Endline \\
\hline Received PNC & 54.1 & 74.5 & 45.7 & 78.4 & 26.3 & 53.6 \\
\hline $\mathrm{N}$ & 783 & 772 & 787 & 790 & 380 & 390 \\
\hline \multicolumn{7}{|l|}{ Timing of PNC visit } \\
\hline Within 48 hours & 16.0 & 75.0 & 3.0 & 82.1 & 52.8 & 77.4 \\
\hline Within 3-7 days & 25.8 & 19.6 & 26.2 & 10.8 & 27.9 & 12.0 \\
\hline Within 2 weeks & 44.6 & 3.7 & 58.8 & 6.6 & 13.9 & 7.2 \\
\hline Within 6 weeks & 13.6 & 1.7 & 11.9 & 0.5 & 5.4 & 3.4 \\
\hline Total & 100.0 & 100.0 & 100.0 & 100.0 & 100.0 & 100.0 \\
\hline$N$ & 426 & 575 & 362 & 619 & 280 & 209 \\
\hline \multicolumn{7}{|l|}{ Reasons for receiving first PNC } \\
\hline Regular check-up & 59.6 & 84.0 & 85.8 & 94.7 & 80.4 & 88.0 \\
\hline Own complications & 21.8 & 9.8 & 13.3 & 4.2 & 15.7 & 11.0 \\
\hline Baby's complications & 4.0 & 2.6 & 0.6 & 0.6 & 0.0 & 0.5 \\
\hline Both child's and own complications & 14.6 & 3.6 & 0.3 & 0.5 & 3.9 & 0.5 \\
\hline Total & 100.0 & 100.0 & 100.0 & 100.0 & 100.0 & 100.0 \\
\hline $\mathrm{N}$ & 426 & 575 & 362 & 619 & 280 & 209 \\
\hline
\end{tabular}


Table 5.17 illustrates that 90 percent of women or more received the first postnatal check-up from facilities in both intervention and control areas. Women from the intervention areas are more likely to seek PNC from public-sector facilities than women from the control area (Intervention: 44\%, 27\%, control: 18\%). PNC uptake from private facilities decreased in the intervention areas while it increased in the control area. More women in the control than in the intervention area reported PNC uptake from private facilities ( $81 \%$ vs $40 \%, 71 \%$ ).

The PNC utilization from the tertiary hospitals and UHFWCs is higher in the intervention areas (Chittagong: 18\%, 34\% and Munshiganj: 65\%, 14\% respectively). On the other hand, in the control area UHC is mostly used for PNC (29\%) followed by tertiary hospital (23\%). It is worth noting women received immediate PNC within 48 hours at the facilities where they gave birth.

TABLE 5.17 Changes in uptake of first postnatal care services by facility and type of provider (in percent)

\begin{tabular}{|c|c|c|c|c|c|c|}
\hline \multirow[t]{3}{*}{ Utilization of PNC } & \multicolumn{4}{|c|}{ Intervention } & \multirow{2}{*}{\multicolumn{2}{|c|}{$\begin{array}{l}\text { Control } \\
\text { Comilla }\end{array}$}} \\
\hline & \multicolumn{2}{|c|}{ Chittagong } & \multicolumn{2}{|c|}{ Munshiganj } & & \\
\hline & Baseline & Endline & Baseline & Endline & Baseline & Endline \\
\hline \multicolumn{7}{|l|}{ Place of PNC } \\
\hline Home & 20.0 & 10.3 & 11.9 & 4.2 & 29.6 & 5.3 \\
\hline Facility & 80.0 & 89.7 & 88.1 & 95.8 & 70.4 & 94.7 \\
\hline Total & 100.0 & 100.0 & 100.0 & 100.0 & 100.0 & 100.0 \\
\hline $\mathrm{N}$ & 426 & 575 & 362 & 619 & 280 & 209 \\
\hline \multicolumn{7}{|l|}{ Type of facility } \\
\hline Public & 32.0 & 44.4 & 14.7 & 27.4 & 20.3 & 17.7 \\
\hline Private & 58.6 & 39.9 & 83.1 & 71.3 & 79.7 & 81.3 \\
\hline NGO & 9.4 & 15.7 & 2.2 & 1.3 & 0.0 & 1.0 \\
\hline Total & 100.0 & 100.0 & 100.0 & 100.0 & 100.0 & 100.0 \\
\hline $\mathrm{N}$ & 341 & 516 & 319 & 593 & 197 & 198 \\
\hline \multicolumn{7}{|l|}{ Public facility } \\
\hline Tertiary hospital & 25.7 & 18.3 & 51.1 & 64.8 & 45.0 & 22.9 \\
\hline District hospital & 0.9 & 7.0 & 2.1 & 4.9 & 2.5 & 17.1 \\
\hline MCWC & 17.4 & 22.7 & 4.3 & 3.1 & 5.0 & 17.1 \\
\hline $\mathrm{UHC}$ & 8.3 & 17.0 & 19.1 & 13.6 & 27.5 & 28.6 \\
\hline UHFWC & 46.8 & 34.1 & 23.4 & 13.6 & 15.0 & 14.3 \\
\hline Community clinic & 0.9 & 0.9 & 0.0 & 0.0 & 5.0 & 0.0 \\
\hline Total & 100.0 & 100.0 & 100.0 & 100.0 & 100.0 & 100.0 \\
\hline $\mathrm{N}$ & 109 & 229 & 47 & 162 & 40 & 35 \\
\hline \multicolumn{7}{|l|}{ Types of provider } \\
\hline Qualified doctor & 61.0 & 58.6 & 61.0 & 68.5 & 56.4 & 68.9 \\
\hline Mid-level provider* & 23.0 & 31.8 & 32.1 & 29.7 & 21.1 & 30.6 \\
\hline Unqualified provider & 16.0 & 9.6 & 6.9 & 1.8 & 22.5 & 0.5 \\
\hline Total & 100.0 & 100.0 & 100.0 & 100.0 & 100.0 & 100.0 \\
\hline $\mathrm{N}$ & 426 & 575 & 362 & 619 & 280 & 209 \\
\hline
\end{tabular}

MCWC=Mother and Child Welfare Center. UHC=Upazila Health Complex. UHFWC=Union Health and Family Welfare Center.

Overall, the non-use of public-sector community level facilities for PNC is evident, which may be explained by the unavailability of providers at those facilities. Like antenatal care, the use of medically trained providers for postnatal care is universal (Chittagong: 90\%, Munshiganj: 98\%, Comilla: 99\%). Irrespective of interventions, consulting a qualified doctor for postnatal check-up was common in all the study areas (Intervention: 59\%, 69\% and Control $69 \%$ ). Use of unqualified providers for PNC is negligible in Munshiganj and Comilla; yet, 10 percent of women in Chittagong reported the use of unqualified providers, which otherwise suggests inadequate performance of community-level qualified providers.

\section{Quality of postnatal care services}

A weighted composite quality score was used to measure the quality of postnatal care services. Like ANC score, a PNC composite score was constructed based on a maximum of three processes or aspects: responsiveness, physical examination, and prevention and case management. A total of 29 indicators were used to calculate composite quality score for PNC services (Appendix 4). Comparison of composite score across the sites reveals more 28 
or less same quality of PNC services being provided at the intervention facilities as reported by clients compared to control facilities.

For PNC services, responsiveness was measured in terms of whether the provider maintained audio and visual privacy for the client, shown supportive behavior, explained the problem, and waiting time to receive the service. Physical examination included measuring client's blood pressure, pulse, and body temperature, checking length of cervix, abdominal pain, vaginal bleeding, vaginal discharge, stich of episiotomy, condition of perineum and the mouth of the uterus, checking anemia, dehydration and edema, and examining breast and nipples. Prevention and case management included whether provider advised on breast feeding and caring of the breasts, uptake vitamin ' $A$ ' capsule, vaccination of baby, the complications after delivery, referral services if the complications occur, asked about the interval of delivery and family planning services, and provided required medicine after delivery.

TABLE 5.18 Quality of care score for postnatal care services (score 0-1)

\begin{tabular}{lrrrrrr}
\hline \multirow{2}{*}{ Aspects of care } & \multicolumn{3}{c}{ Intervention } & \multicolumn{2}{c}{ Control } \\
\cline { 2 - 7 } & \multicolumn{2}{c}{ Chittagong } & \multicolumn{2}{c}{ Munshiganj } & \multicolumn{2}{c}{ Comilla } \\
\cline { 2 - 7 } & Baseline & Endline & Baseline & Endline & Baseline & Endline \\
\hline Responsiveness & 0.73 & 0.63 & 0.59 & 0.49 & 0.70 & 0.64 \\
Physical examination & 0.28 & 0.20 & 0.13 & 0.20 & 0.26 & 0.15 \\
Prevention and case management & 0.70 & 0.83 & 0.39 & 0.70 & 0.81 & 0.82 \\
Composite score (weighted) & 0.49 & 0.48 & 0.28 & 0.41 & 0.52 & 0.45 \\
N & $\mathbf{3 4 1}$ & $\mathbf{5 1 6}$ & $\mathbf{3 1 9}$ & $\mathbf{5 9 3}$ & $\mathbf{1 9 7}$ & 198 \\
\hline
\end{tabular}

Overall, quality score on PNC services provided at facilities is low in both intervention and control areas (Intervention: 0.48, 0.41; Control: 0.45). Variability is observed over time for each of the processes. Like ANC, quality score was highest for prevention and case management in both intervention and control areas, with a score of 0.70 and above. Quality score on physical examination was the lowest not exceeding a score of 0.20 . Munshiganj is credited for the increase in the quality score of PNC services from 0.28 to 0.41 due to the improvements in prevention and case management (Table 5.18). 


\section{USE OF CONTRACEPTION}

Table 5.19 shows the use of family planning methods in all three districts. Before the interventions, nearly 60 percent of women had used any FP method to delay or avoid pregnancy in all three districts. After a 12-month period, the use of contraception remains almost the same in the intervention areas, while it decreased about 13 percentage points in the control area.

In all three districts, the use of contraception is skewed towards short-acting modern methods. The pill is the most popular method for contraception (Chittagong: 31\%, Munshiganj: 23\%, Comilla; 24\%) followed by the condom and injectable.

Findings suggest a small increase in the acceptance of IUDs and implants. Yet, only 9 percent or less women accepted any long-acting or permanent method. Chittagong is credited for higher use of IUDs and implants. On the other hand, use of traditional methods decreased in both intervention and control districts.

Overall, the use pattern of modern methods in 30 study unions is different from the national modern method mix. Our findings reflect the use of contraception within the 12 months postpartum while national estimates provide the use pattern of all reproductive aged married women.

TABLE 5.19 Changes in the use of family planning methods over time (in percent)

\begin{tabular}{|c|c|c|c|c|c|c|}
\hline \multirow[t]{3}{*}{ Use of Contraception } & \multicolumn{4}{|c|}{ Intervention } & \multirow{2}{*}{\multicolumn{2}{|c|}{$\begin{array}{l}\text { Control } \\
\text { Comilla }\end{array}$}} \\
\hline & \multicolumn{2}{|c|}{ Chittagong } & \multicolumn{2}{|c|}{ Munshiganj } & & \\
\hline & Baseline & Endline & Baseline & Endline & Baseline & Endline \\
\hline Using any method & 59.1 & 58.5 & 55.3 & 57.0 & 57.9 & 44.6 \\
\hline $\mathrm{N}$ & 783 & 767 & 787 & 786 & 380 & 783 \\
\hline \multicolumn{7}{|l|}{ Use of contraception } \\
\hline Modern- Long Acting & 5.9 & 8.9 & 7.5 & 8.6 & 9.5 & 7.7 \\
\hline Female sterilization & 1.8 & 1.4 & 6.2 & 4.9 & 5.3 & 3.1 \\
\hline Male sterilization & 0.1 & 0.1 & 0.0 & 0.4 & 0.0 & 0.0 \\
\hline IUD & 1.3 & 2.6 & 0.6 & 0.8 & 0.8 & 1.5 \\
\hline Implant & 2.7 & 4.8 & 0.6 & 2.5 & 3.4 & 3.1 \\
\hline Modern- Short Acting & 50.8 & 48.1 & 45.4 & 46.1 & 45.5 & 36.4 \\
\hline Injectable & 7.2 & 6.7 & 6.7 & 6.8 & 10.8 & 7.2 \\
\hline Oral pill & 30.4 & 30.7 & 22.6 & 22.5 & 26.3 & 24.1 \\
\hline Condom & 13.3 & 10.6 & 16.0 & 16.7 & 8.4 & 5.1 \\
\hline Traditional & 2.4 & 1.6 & 2.4 & 2.3 & 2.9 & 0.5 \\
\hline Safe period/Periodic abstinence & 1.7 & 1.2 & 1.0 & 1.6 & 2.4 & 0.3 \\
\hline Withdrawal & 0.8 & 0.4 & 1.4 & 0.6 & 0.5 & 0.3 \\
\hline $\mathrm{N}$ & 463 & 452 & 435 & 450 & 220 & 174 \\
\hline
\end{tabular}




\section{PROVIDER COMPETENCE}

The FWVs from 24 intervention UHFWCs who were interviewed prior to the interventions were interviewed after 12 months to assess knowledge and skills related to normal delivery services. Provider competence is defined as possessing sufficient knowledge and skills to comply with maternal health care standard practices. In assessing provider knowledge and skills, an arbitrary composite competency score was used.

\section{Provider profile}

The average age of the FWVs is 45 , with no remarkable differences between the two intervention districts. Not all FWVs received training on maternal health services along with the other training necessary to provide delivery services. All FWVs in Chittagong felt that they needed further training, while a slightly lower proportion expressed such a need in Munshiganj (92\%). The types of training emphasized were: midwifery, active management of the third stage of labor, use of partograph, acute respiratory infection, and integrated management of childhood illness (not shown).

\section{Counselling skills}

FWVs' maternal health care counseling skills were assessed on three broad aspects: general counseling (6 indicators), birth planning counseling ( 8 indicators), and advice on discharge after delivery (6 indicators). To obtain a summary performance of FWVs, an arithmetic method is used to estimate the competency score from selected indicators for each aspect of care.

Overall, the counseling skills of FWVs was not encouraging, not exceeding a combined score of 0.63 out of 1.00 . The level of counseling competency is higher in Chittagong than Munshiganj. Of the three aspects of counseling, "general counseling" earned the highest score (Chittagong: 0.74, Munshiganj: 0.57), and it increased in both areas in the past 12 months. Scores on "advice on discharge after delivery" and "birth planning" increased in Munshiganj but decreased in Chittagong over time (Figure 5.3). Low scores on maternal health counseling can be accounted for by lack of opportunities for in-service training or absence of regular supportive supervision.

FIGURE 5.3 Counseling skills of FWVs on maternal health services (score $0-1$ )

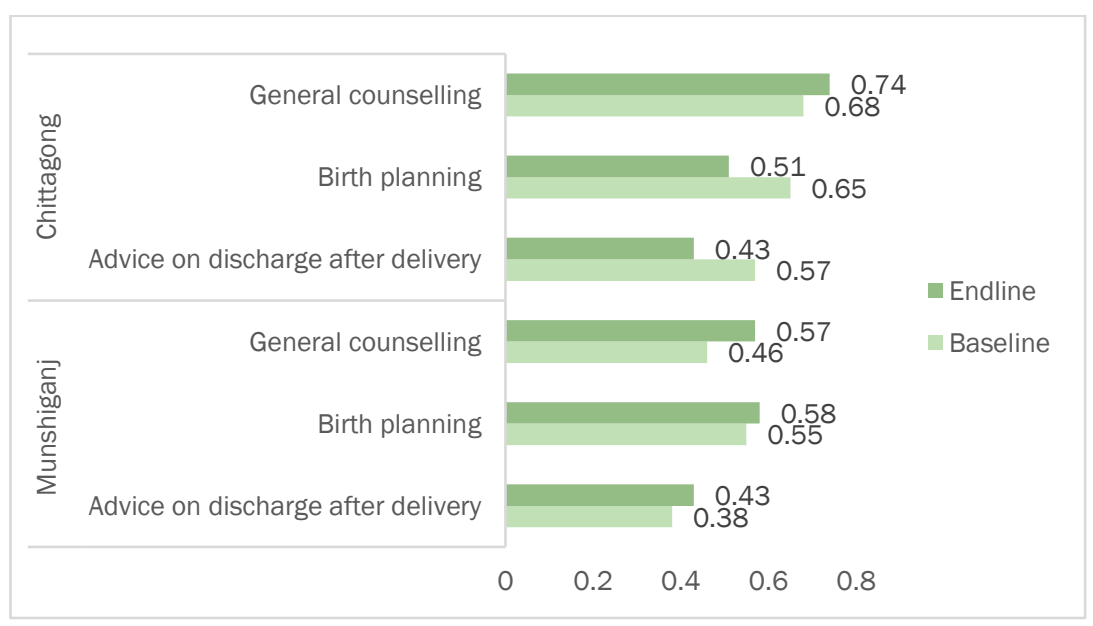

\section{Knowledge of complications}

In rural areas, EmOC services are available at the upazila-level hospitals and above. UHFWCs are not required to provide EmOC services and FWVs are entrusted with the responsibility to provide normal delivery services and identify delivery complications and refer those cases to higher-level facilities. 
A composite index on provider knowledge on possible complications during pregnancy, during delivery and after delivery was constructed using the data collected through provider interviews. A total of 8 indicators were used to calculate the score for pregnancy complications ${ }^{3}, 12$ indicators for delivery complications ${ }^{4}$ and 8 indicators for postpartum complications ${ }^{5}$. A weighted score on a 0-1 scale is used to measure the provider knowledge on possible complications during pregnancy, during delivery and after delivery.

Figure 5.4 reveals an increase in the provider knowledge on possible complications during pregnancy, during delivery and after delivery in both intervention districts over time. Comparison of quality scores across antenatal, delivery and postnatal complications reveals higher provider knowledge on pregnancy complications and greatest improvement in the knowledge score for delivery complications. The composite knowledge score is highest for pregnancy complications in Chittagong ( 0.79 out of 1.00) while it is lowest for delivery complications in Munshiganj (0.63 out of 1.00). Despite an increase, overall knowledge of delivery and post-partum complications ranges between 0.63 and 0.68 across sites, far below the optimum 6 level. This is a cause for concern as provider knowledge of the possible complications during delivery is essential to recognize problem and reduce the delay in referring women for appropriate care. Limited knowledge of FWVs on delivery and post-partum complications suggest that they need training and clinical supervision.

FIGURE 5.4 Knowledge of FWVs on possible complications during pregnancy, during delivery, and after delivery (score 0-1)

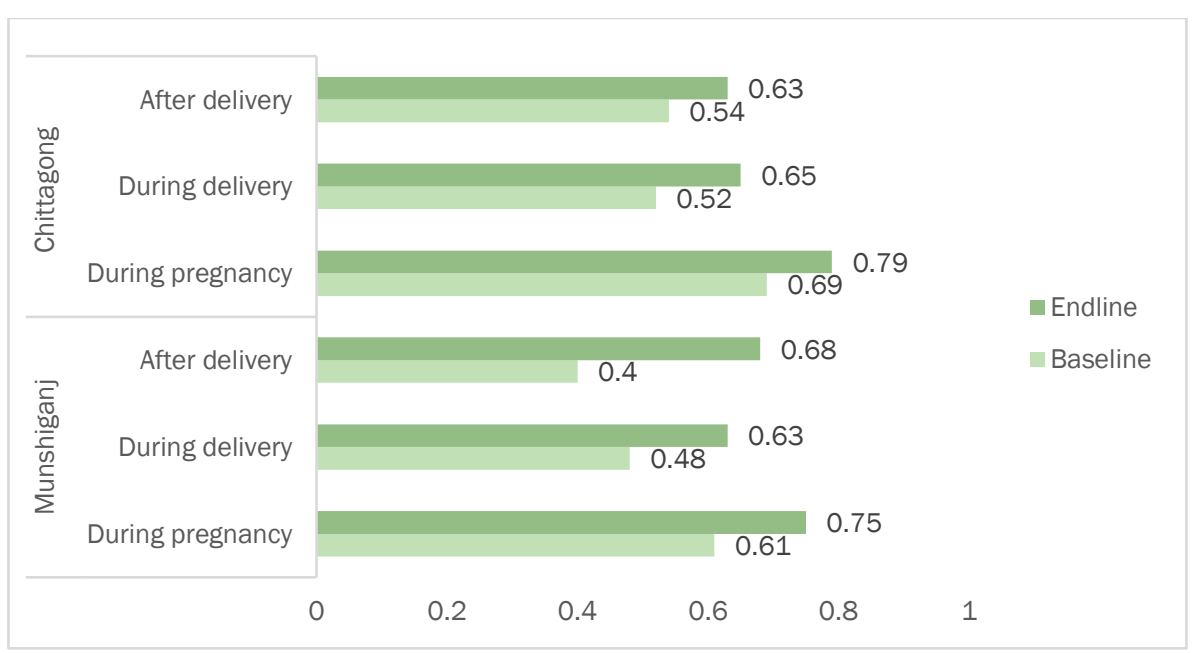

\section{Obstetric skills}

The competency of maternal healthcare clinical skills was higher among FWVs in Chittagong (0.90 out of 1.00) while it is lowest in Munshiganj ( 0.60 out of 1.00). Most FWVs reported possessing the skills to inject intravenous infusions, practice bimanual examination, perform speculum examination, suture episiotomy, and repair vaginal laceration. In contrast, the use of partograph to manage labor decreased over time. At the time of endline survey, only 2 out of 24 FWVs reported using a partograph compared to 5 FWVs reported at the baseline survey (Table 5.20). It is critical that all the FWVs are skilled in using a partograph to manage labor; otherwise, there will be risk in recognizing obstetric complications.

\footnotetext{
${ }^{3}$ Severe headache, blurry vision, high blood pressure, pre-eclampsia, convulsion/eclampsia, excessive vaginal bleeding, high fever and swelling feet.

${ }^{4}$ High blood pressure, pre-eclampsia, convulsion/eclampsia, excessive vaginal bleeding, high fever, swelling feet, excessive water leaking, baby's hand and feet came first, prolonged labor, obstructed labor, retained placenta and ruptured uterus.

${ }^{5}$ Severe headache, blurry vision, high blood pressure, pre-eclampsia, convulsion/eclampsia, excessive vaginal bleeding, high fever and swelling feet.

${ }^{6} \mathrm{~A}$ score of 0.80 out of 1.00 is arbitrarily set as an "optimum score" after assessing the necessity of individual indicators in offering the specified service. 
TABLE 5.20 Clinical skills of FWVs on maternal health care (in number)

\begin{tabular}{|c|c|c|c|c|c|c|}
\hline \multirow[t]{2}{*}{ Indicators } & \multicolumn{2}{|c|}{ Chittagong } & \multicolumn{2}{|c|}{ Munshiganj } & \multicolumn{2}{|c|}{ Total } \\
\hline & Baseline & Endline & Baseline & Endline & Baseline & Endline \\
\hline Use partograph to manage labor & 1 & - & 4 & 2 & 5 & 2 \\
\hline Provide intravenous infusions & 15 & 12 & 12 & 12 & 27 & 24 \\
\hline Suture episiotomy & 13 & 11 & 10 & 6 & 23 & 17 \\
\hline Suture (repair) vaginal laceration & 12 & 9 & 10 & 11 & 22 & 20 \\
\hline Perform speculum examination & 13 & 12 & 12 & 7 & 25 & 19 \\
\hline Perform menstrual regulation & 12 & 10 & 8 & 5 & 20 & 15 \\
\hline $\mathrm{N}$ & 15 & 12 & 12 & 12 & 27 & 24 \\
\hline Composite score & 0.73 & 0.90 & 0.78 & 0.60 & 0.75 & 0.67 \\
\hline Composite score without partograph & 0.87 & 0.90 & 0.87 & 0.68 & 0.87 & 0.79 \\
\hline
\end{tabular}




\section{Program Effectiveness}

\section{COMMUNITY MOBILIZATION}

UHFWC Management Committees have been reactivated in 18 unions to manage the facility and mobilize resources through active community participation. The committees were reactivated through Action Plan workshops attended by members of the UHFWC Management Committees, UHFWC service providers, and upazila program managers. The workshops resulted in obtaining the commitment of the committees to improve UHFWC readiness, repair facilities as much as possible, raise funds for UHFWCs, and increase awareness among people about 24-hour delivery services of UHFWCs. These committees created a "community fund" for the UHFWC with the contribution of Union Parishad ${ }^{7}$ (UP), community members, and local bazaar committees, which is used to improve physical conditions of the UHFWC, conduct emergency maintenance, and subsidize referral transportation costs if needed. To maintain transparency on the management of the fund, accumulations of funds, expenditures, and current balances are presented at monthly meetings and published on a notice board at the UHFWC for public viewing. Committee members use monthly meetings as a platform to manage and monitor UHFWCs for round-the-clock normal delivery services. Monthly meetings also allow to ensure active involvement of members of the UHFWC Management Committee.

\section{COMMUNITY MONITORING AND RESOURCE MOBILIZATION}

The community was involved in the project to ensure the readiness of the facilities for 24-hour normal delivery services, to manage and use the community fund and to create demand in the community for UHFWC services. Monthly monitoring data for 12 intervention months was used to measure the sustainability of the community involvement in local health services management.

Organizing monthly meetings of Management Committees attended by local government representatives is the key success of community involvement efforts. A composite score (0-1 scale) was constructed based on 5 indicators whether meetings were held as planned, more than 50 percent of members attended the meeting, UP Chairman chaired the meeting, previous meeting's decisions were followed up, and new issues were discussed and decisions were taken accordingly. Overall, the score on sustaining effective meetings is 0.66 for Munshiganj and 0.80 for Chittagong. Seven out of 18 unions earned a score higher than 0.80 (Chittagong: 5 , Munshiganj: 2).

To measure the management process of community fund, 4 indicators were used, e.g., whether new fund was added, community fund or community donation used for improving UHFWC readiness, monthly balance sheet of fund prepared, and balance sheet of fund displayed/shared in the meeting. Overall, the score on community fund is 0.44 for Munshiganj while Chittagong earned an even lower score (Table 6.1). Financial contribution is lower in Chittagong compared with Munshiganj. Initially, Management Committee members were more enthusiastic and made large contributions to the community fund, but in the later months of the intervention the interest of community members waned. Only one out of 18 unions earned a score over 0.60 (Betka Union: 0.67).

\footnotetext{
7 Lowest tier of the government's administrative unit, in rural location with the jurisdiction of approximately $30,000-40,000$ population. 
The combined score of these two community mobilization activities is nearly 0.60 , which means communities are in favor of improving local health facilities. The interest and commitment of community members is marginally stronger in Chittagong than Munshiganj. Yet, Chittagong exhibits a blend of extreme performance-the score on community monitoring of UHFWC (0.80) highly contrasted the score on the management of community fund $(0.33)$. On the other hand, Munshiganj performed moderately-the gap between two aspects of community management is small (Table 6.1).

TABLE 6.1 Sustainability score on community participation (score 0-1)

\begin{tabular}{|c|c|c|c|c|c|c|c|c|c|c|}
\hline \multirow[b]{2}{*}{ Munshiganj } & \multicolumn{3}{|c|}{ Louhajong } & \multicolumn{3}{|c|}{ Sreenagar } & \multicolumn{3}{|c|}{ Tongibari } & \multirow{2}{*}{$\begin{array}{c}\text { Total } \\
\text { Score } \\
(\%)\end{array}$} \\
\hline & Baultoli & Holdia I & Kanakshar & Atpara & Beertara & Hashara & $\begin{array}{c}\text { Ariol } \\
\text { Baligaon }\end{array}$ & Betka & $\overline{\text { Kamarkhara }}$ & \\
\hline $\begin{array}{l}\text { Management } \\
\text { Committee } \\
\text { Meeting }\end{array}$ & 0.65 & 0.67 & 0.88 & 0.42 & 0.60 & 0.72 & 0.53 & 0.88 & 0.63 & 0.66 \\
\hline $\begin{array}{l}\text { Community } \\
\text { Fund }\end{array}$ & 0.50 & 0.46 & 0.42 & 0.31 & 0.31 & 0.52 & 0.42 & 0.67 & 0.40 & 0.44 \\
\hline Total & 0.59 & 0.58 & 0.67 & 0.43 & 0.52 & 0.63 & 0.51 & 0.74 & 0.55 & 0.58 \\
\hline \multirow[b]{2}{*}{ Chittagong } & \multicolumn{3}{|c|}{ Anwara } & \multicolumn{2}{|c|}{ Boalkhali } & \multicolumn{2}{|c|}{ Patiya } & \multicolumn{2}{|c|}{ Sitakunda } & Total \\
\hline & Barshot & Boirag & Haildhor & Chorondee & Shakpura & $\begin{array}{c}\text { Char- } \\
\text { pathortghata }\end{array}$ & Kushumpura & Shonaichhori & Solimpur & $\begin{array}{c}\text { Score } \\
(\%)\end{array}$ \\
\hline $\begin{array}{l}\text { Management } \\
\text { Committee } \\
\text { Meeting }\end{array}$ & 0.73 & 0.75 & 0.83 & 0.90 & 0.88 & 0.85 & 0.70 & 0.88 & 0.68 & 0.80 \\
\hline $\begin{array}{l}\text { Community } \\
\text { Fund }\end{array}$ & 0.31 & 0.48 & 0.35 & 0.25 & 0.50 & 0.31 & 0.40 & 0.21 & 0.17 & 0.33 \\
\hline Total & 0.55 & 0.63 & 0.62 & 0.61 & 0.71 & 0.61 & 0.56 & 0.58 & 0.45 & 0.59 \\
\hline
\end{tabular}

Community contribution is critical for timely repair and maintenance of facilities and supplies of necessary equipment. Facilities do not wait for a long bureaucratic approval to address emergency maintenance and supplies. Immediate maintenance and repair has been possible after the reactivation of Management Committee and introduction of community fund for UHFWC. During the intervention period, the Management Committees succeeded in carrying out civil works for UHFWCs, e.g., painting of facility building, construction of boundary wall, and repair of drainage system and approach road, which had remained unaddressed until the project started. Emergency maintenance, e.g., repair of pump, sinking tube-well, repair of generator, restarting electricity supply, installing solar panel, and repair of toilet was carried out during the intervention period as needed (Table 6.2).

Committee members routinely monitored the availability of human resources, facility readiness, and supplies to ensure 24-hour normal delivery services. For example, they purchased essential medical equipment for the labor room of UHFWCs, including delivery/operating table, oxygen cylinder, blood pressure machine, and weight machine (Table 6.2). 
TABLE 6.2 Community contribution to 18 intervention UHFWCs (in number)

\begin{tabular}{|c|c|c|c|}
\hline Item & Chittagong & Munshiganj & Total \\
\hline \multicolumn{4}{|l|}{ Physical } \\
\hline Water supply (pump repair/tube well) & 1 & 3 & 4 \\
\hline Power supply line repair/generator/ solar panel & 3 & 4 & 7 \\
\hline Toilet repair and cleanliness & 0 & 2 & 2 \\
\hline Fan/light & 5 & 6 & 11 \\
\hline Furniture (chair/table/delivery bed/shelf for medicine) & 0 & 4 & 4 \\
\hline Facility building painting & 0 & 3 & 3 \\
\hline Boundary wall construction & 0 & 1 & 1 \\
\hline Drainage system repair & 1 & 1 & 2 \\
\hline Approach road repair & 2 & 2 & 4 \\
\hline \multicolumn{4}{|l|}{ Clinical } \\
\hline Delivery/operating table & 0 & 1 & 1 \\
\hline Oxygen cylinder & 0 & 1 & 1 \\
\hline Blood pressure machine & 0 & 2 & 2 \\
\hline Weight machine & 0 & 1 & 1 \\
\hline $\mathrm{N}$ & 9 & 9 & 18 \\
\hline
\end{tabular}

\section{WOMEN'S AWARENESS OF COMMUNITY MOBILIZATION ACTIVITIES}

Findings reveal a low awareness on the Management Committee and community fund among women. Only 14 percent of women heard about the UHFWC Management Committee. Fieldworkers and family/community members and UHFWC providers are the key sources of such information. Sources of information varied between intervention districts. The majority of women in Chittagong had known about the committee through fieldworkers (58\%) while in Munshiganj family/community members (58\%) emerged as the primary source.

TABLE 6.3 Respondent's knowledge regarding UHFWC Management Committee and Community Fund (in percent)

\begin{tabular}{|c|c|c|c|}
\hline Characteristics & Chittagong & Munshiganj & Total \\
\hline Knows/heard about UHFWC Management Committee & 16.9 & 11.4 & 14.1 \\
\hline $\mathrm{N}$ & 579 & 595 & 1,174 \\
\hline \multicolumn{4}{|l|}{ Source of information* } \\
\hline Service provider of UHFWC & 26.3 & 24.6 & 25.6 \\
\hline Fieldworker & 57.6 & 36.2 & 48.8 \\
\hline Chairman/Member of UP & 3.0 & 13.0 & 7.1 \\
\hline Husband/friend/relative/neighbor & 26.2 & 58.4 & 39.9 \\
\hline $\mathrm{N}$ & 99 & 69 & 168 \\
\hline Heard about Community Fund & 9.5 & 14.6 & 12.1 \\
\hline $\mathbf{N}$ & 579 & 595 & 1,174 \\
\hline \multicolumn{4}{|l|}{ Source of information* } \\
\hline Service provider of UHFWC & 17.5 & 18.4 & 18.1 \\
\hline Fieldworker & 68.4 & 16.1 & 36.8 \\
\hline Chairman/member of UP & 8.8 & 10.3 & 9.7 \\
\hline Husband/friend/relative/neighbor & 22.9 & 72.4 & 52.8 \\
\hline $\mathrm{N}$ & 57 & 87 & 144 \\
\hline
\end{tabular}

* Multiple responses

Awareness on the community fund was even lower. Fieldworkers and family/community members are the main channels through which women learned about the community fund. In Chittagong, the role of fieldworkers in informing women about the community fund is highly remarkable (68\%) while Munshiganj exhibited negligible efforts of fieldworkers (16\%). Community interaction is greater in Munshiganj as three quarters of women knew about the community fund from family/community members. Only 10 percent of women or less mentioned local government representatives as another source, which suggests their limited involvement in community awareness about the project benefits (Table 6.3). Monitoring data reveal that in a few unions, UHFWC Management Committees organized awareness building activities, e.g., courtyard meetings among pregnant mothers and public announcement in the community (not shown). 
Women were asked what changes of the UHFWC they observed in the past 12 months. It is evident from Table 6.4 that the interventions have resulted in the improvement of UHFWCs and their services. Key physical improvements included repair of facility building (20\%), painting of facility building (17\%), repair/construction of approach road (5\%), and security of the UHFWC (6\%). Munshiganj experienced greater improvement in physical facilities than Chittagong.

Improvement in UHFWC services was widely reported by women. The 24-hour availability of skilled service provider is the key improvement perceived by nearly 30 percent of women. Introduction of normal delivery service is another widely mentioned service improvement. Women also admitted the availability of free-of-cost treatment. Overall, service improvement was more intensely perceived by the women from Chittagong than from Munshiganj.

TABLE 6.4 Physical improvement and service improvement of UHFWCs in the last one year reported by respondents (in percent)

\begin{tabular}{|c|c|c|c|}
\hline Improvements & Chittagong & Munshiganj & Total \\
\hline \multicolumn{4}{|l|}{ Physical improvement * } \\
\hline No improvement & 32.9 & 32.7 & 32.8 \\
\hline Facility building repaired & 17.1 & 22.8 & 19.7 \\
\hline Facility building painted & 14.2 & 19.9 & 16.8 \\
\hline $\begin{array}{l}\text { Improvement of communication system through road } \\
\text { construction/repair }\end{array}$ & 3.4 & 7.0 & 5.0 \\
\hline Security of the UHFWC ensured & 7.0 & 4.4 & 5.8 \\
\hline $\mathrm{N}$ & 415 & 344 & 759 \\
\hline \multicolumn{4}{|l|}{ Service improvement * } \\
\hline Introduction of normal delivery service & 25.5 & 25.9 & 25.7 \\
\hline 24-hour availability of skilled service provider & 32.0 & 23.9 & 28.3 \\
\hline Availability of free-of-cost treatment & 19.7 & 13.7 & 17.0 \\
\hline Free medicine & 10.1 & 9.9 & 10.0 \\
\hline Service provided by female service provider & 16.8 & 5.0 & 11.5 \\
\hline No improvement & 4.1 & 11.1 & 7.2 \\
\hline $\mathrm{N}$ & 415 & 344 & 759 \\
\hline
\end{tabular}

*Multiple responses.

UHFWCs are mainly used for ANC and family planning services by women. Women were asked why the majority of ANC seekers did not use UHFWC for normal delivery services. More than half of the respondents identified lack of publicity about the availability of 24-hour normal delivery service as the main reason for such low use of UHFWC (Table 6.5). Unavailability of delivery complications management services is another reason that women do not opt for UHFWC for delivery services (20\%). Shortage of service providers (19\%) and inadequate skills of providers (13\%) were other major contributors to the low use of UHFWC for delivery care among ANC seekers.

TABLE 6.5 Reasons for low use of UHFWCs for deliveries among women who sought ANC (in percent)

\begin{tabular}{|c|c|c|c|}
\hline Reasons* & Chittagong & Munshiganj & Total \\
\hline Lack of publicity of 24-hour normal delivery service & 57.6 & 50.0 & 53.8 \\
\hline Non-availability of service providers & 15.3 & 23.0 & 19.2 \\
\hline Lack of training of service providers & 9.7 & 15.2 & 12.5 \\
\hline Unavailability of delivery complication management provision & 21.1 & 18.7 & 19.9 \\
\hline $\begin{array}{l}\text { Inadequate readiness of labor room/ } \\
\text { Lack of delivery equipment and medicine }\end{array}$ & 18.6 & 13.9 & 16.4 \\
\hline Lack of security & 4.3 & 1.8 & 3.0 \\
\hline Communication/transportation problem & 4.8 & 4.4 & 4.6 \\
\hline $\mathrm{N}$ & 772 & 790 & 1,562 \\
\hline
\end{tabular}




\section{Stakeholders' Views}

\section{PROGRAM MANAGER PERSPECTIVES}

Of the 9 program managers interviewed (national=1, district=2, upazila=6), five were under 50 and the remaining four managers were aged 50 years or older. All managers were involved with the implementation of the project.

\section{A. Human resources}

No program managers observed any problems faced by FWVs to provide round-the-clock normal delivery services along with other services at the UHFWC. The majority of the managers stated that UHFWC service providers became more attentive to their work and ascribed the reactivation of Management Committee to the improvement of UHFWC service quality. FWVs have shown sincere commitment to provide $24 / 7$ normal delivery services. Yet, they confront some physical and social challenges to perform their responsivities. For example,

“...it is a 24-hour service, FWVs need to attend delivery clients no matter what time it is. If any complications, FWVs need to refer clients. Unfortunately, there is no ambulance or emergency vehicle for referral transportation. In the course of dealing complicated cases, adverse events, e.g., maternal deaths occur. People do not understand or give support in such situations, rather they harass service providers. Even worse, sometimes local government representatives and mass people intimidate our providers and make their life difficult." - Upazila-level medical officer, Munshiganj

"It is not necessary that FWVs have to be present 24 hours a day at the UHFWC. When delivery clients come to the UHFWC, they call FWVs. It is the responsibility of FWVs to provide $24 / 7$ delivery services. FWVs do not complain about giving delivery service $24 / 7$. However, they often complain about the infrastructure, electricity and water supply, which need to be improved." - District FP manager

Improvements in service delivery as an outcome of the introduction of quarterly review meetings was widely mentioned by the managers. The managers perceived several benefits of the project review meetings. For example, the meetings inspired service providers to increase their effort for delivery service, increased supervision and monitoring by managers, identified and addressed gaps in the facility readiness, and improved service quality and quantity of UHFWCs.

\section{B. Facility readiness}

Manager's opinion on the readiness of UHFWC to provide 24-hour delivery services was collected. Lack of facility readiness was the key limitation in UHFWC service delivery as identified by the majority of managers. Encouragingly, some improvements in physical facilities were observed during the project period. In a few cases, the role of Upazila Nirbahi Officer (UNO) and other government officials was critical in improving health facility infrastructure, including the residence of UHFWC providers. Two program managers from Chittagong noted that residential quarters have been repaired to ensure 24-hour availability of service providers in the facility compound.

Not always necessary equipment was available. Half of the managers reported full availability of necessary equipment. Managers reported several DGFP-introduced improvements that took place during the project period. For example, DGFP sanctioned a budget for UHFWCs to buy mattress, pillow, and mosquito net for delivery and recovery rooms. DGFP also distributed safe delivery kits to the intervention UHFWCs.

Program managers highlighted lack of clinical readiness for providing delivery services, e.g., no provision for delivery complications management. Non availability of transportation for referral purpose (no provision of emergency vehicle) was also underlined. One program manager each from Chittagong and Munshiganj explained that due to lack of complications management provision and vehicle for referral, sometimes adverse incidents occur, especially 
at night, which causes public incitement. In such situation, service providers do not get the support and cooperation from local government representatives.

The risks of unavailability of delivery complications management and referral transportation was reflected by one local FP manager. For example:

"UHFWCs have almost everything needed for a normal delivery, e.g., infrastructure, workforce, logistics and supplies. However, there is no provision for complications management or cesarean delivery. This is a big problem. In case of emergency or immediate cesarean operation, UHFWC providers are unable to give any service. An ambulance is needed to send a patient to a government hospital within half-an-hour when referred. We do not have such referral transportation, and this is the biggest problem. As we do not have the provision for surgical interventions at the UHFWC, the availability of a vehicle to send patient to upazila health complex or district hospital is very important." - Upazila-level medical officer, Chittagong

\section{Reactivation of UHFWC Management Committee}

The majority of the managers admitted the reactivation of UHFWC Management Committee as a significant improvement that happened during project period. Five out of 6 upazila managers had direct experience of participating at the monthly meetings of Management Committees. Overall, two-thirds of all managers asserted that committee would be able to work independently after the end of project activities. The commitment of SACMO and FWV in keeping the committee active was highly appreciated by the program managers. Recommendations to keep the UHFWC Management Committee active after the end of project period include: regular monitoring and supervision by managers, regular monthly meetings, and discussion on UHFWC Management Committee resolutions at upazila-level meetings.

\section{Community fund for emergency maintenance}

In intervention districts, six out of eight managers were aware of the physical improvement of UHFWCs through community fund. Managers recommended three steps to increase local people's participation and to continue the fund collection after the end of project: community sensitization; role of UHFWC provider; and create demand for facility-based delivery. As part of community mobilization, managers emphasized local-level advocacy to build ownership among community members for joint GOB-community management of UHFWCs. A few managers emphasized to mobilize local government representatives to give money for UHFWC improvement and to sensitize local influential and rich people for contributing to the community fund. For local-level advocacy, involvement and active role of SACMOs and FWVs was considered critical. Demand generation among community members for institutional delivery was perceived another way of mobilizing community support for the UHFWC for which maintaining good physical infrastructure to attract people's attention remains a prerequisite.

\section{E. Connecting women with UHFWC providers}

Two-way communication. The managers were in favor of continuing phone contact with pregnant women following the list of pregnant mothers after the end of project. The use of community fund for follow-up of pregnant mothers was proposed. Program managers were ambitious to create community fund for every UHFWC.

"FWVs will continue to call following pregnant mothers list after the project and associated phone bills can be covered from the community fund. For this, we need to create fund at every union. I believe in absence of fund; they will not stop calling pregnant women. It is their duty...We are thinking of giving smart phone to FWVs for following up pregnant women. These phones will have an application with instructions on 24-hour delivery service, e.g., what to do in case of complications and preparedness for delivery at night." - National program manager

Strengthening referral linkage. Improvements of referral system is known to several program managers. They were aware of the key interventions which contributed to strengthen referral linkages, which include: FWVs refer 
complicated cases with referral slip; introduction of referral slip helps to expedite client's treatment at the referral facilities; and list of CNG (motorized three wheelers) drivers with mobile numbers for emergency referral transportation.

The introduction of referral slip allows pregnant women to receive more attention and importance at higher-level facilities. For example:

"The referral system was improved significantly during this project. The project introduced a referral slip which in my opinion carries much value. Because of this slip, whenever a FWV refers a client to upazila hospital and medical college hospital, the duty doctor of these hospitals easily understands who sent this client. The slip carries information on patient's name, age, other diagnosis, and reason of referral, which is very important for next steps of treatment and the slip also speeds up the service delivery process." - Upazila-level medical officer, Chittagong.

Often, women do not avail the benefits from the public facilities. Even after being referred to higher-level public hospitals, they go to private clinics. One local-level manager observed:

"Now every UHFWC has a list of local CNG drivers with phone numbers. In case of emergency, day or night, CNG drivers take pregnant women to the referral facility. Unfortunately, most women do not go to the prescribed referral facility, but go to a facility whichever they like." - Upazila-level medical officer, Munshiganj

\section{F. Reasons for home delivery}

Broadly, three reasons were identified through program manager interviews for women's interest in home delivery. Only a few managers elaborated on the reasons for home delivery as the rate of home delivery is much lower in Chittagong and Munshiganj compared with the national average. The perception that institutional delivery means cesarean delivery refrains women from going to the facility for delivery care. Gender-sensitive cultural conservativeness is another reason for home delivery.

"Many women feel safe at their own home as their relatives can take care of them and the baby. Many women believe hospitals are interested only in cesarean delivery. In some cases, husbands do not want their wife to be touched or seen by men during delivery. So, they avoid hospitals and think just like their mother or grandmother, their wife should deliver at home. It is a tradition for them." - Upazila FP manager, Chittagong

\section{G. Preference for private facilities}

The program managers were asked the reasons behind women's preference for private facility over public facility in case of referral. Two-thirds of the managers mentioned that the better infrastructure, equipment, cleanliness and service attracted women to private hospitals. Trust of the women about the services provided at private hospital is another widely mentioned reason (4 out of 9 managers). Specifically, two managers mentioned absence of cesarean delivery provision at UHFWCs and many upazila-level government facilities as another reason for women opting for private facilities. Affordability of household allowed women to seek services from private- rather than public-sector facilities. Availability of private clinics in the proximity is another reason for choosing private clinics instead of public facilities. The managers further explained that when people are financially able to pay for the services, it is normal for them to choose the better services. For example:

"People believe they will get better service at private hospital... UHFWC providers refer pregnant women to UHCs, but the problem is that most UHCs do not have the provision for cesarean delivery. So, people go to local private clinics for cesarean delivery. It is easier for them." - National program manager

"People go to private hospitals because they can afford it. People want quality service. Although public hospitals provide quality services, they do not have many physical amenities like private facilities. Government service providers have the best trainings, they are placed in the remote areas to provide 
service, but the infrastructure is not in a suitable condition to provide required services. There are many private hospitals in rural areas, and people can easily go there for better environment and services."

- Upazila FP manager, Munshiganj

"Public hospitals do not have required facilities. In private hospitals people get everything- availability of doctor and nurse, better service, and good behavior. People do not want to take risks. Though private hospitals are expensive, they guarantee good service. Most importantly, most of the people do not have financial problems." - Upazila-level medical officer, Munshiganj

\section{H. Program effectiveness}

Effective interventions. The managers were asked to identify effective interventions of the project. Community involvement to improve service readiness of the facility was strongly perceived by all managers except one. The reactivation of the Management Committee with active involvement of local government representatives is mentioned as the most effective activity of the project. Establishing a community fund with contributions of the UHFWC Management Committee members and bazaar committees is seen as an important step for mobilizing resources for facility improvement. The project is highly credited for creating community fund through which local people contribute to improve the physical infrastructure of UHFWCs (4 out of 9 providers). For example:

"Most effective side of this project is that it successfully connects local government and people with UHFWC. Union Parishad Chairman and Members, and rich and important persons in the community are now involved with the management of UHFWCs. Local people now contribute to repair and paint facility building, repair roads and similar other maintenance work." - District FP manager

"Reactivating the committees was a great initiative. If continued, the committee will be able to promote awareness among people, which in turn will increase delivery at UHFWC. In fact, the use of UHFWC for normal delivery services increased because of this project. Also, the project successfully involved the local government in UHFWC. In the past we tried it, but local government representatives never gave time. But now they are working for the improvement of UHFWC." - Upazila-level medical officer, Munshiganj

Less effective interventions. The opinion of the managers on what activities not achieving the expected outcome was sought. A few managers mentioned some challenges that impeded the project to achieve desired outcome. One-third of the managers were skeptical of the infrastructural development of the facilities, particularly, lack of community contribution to improve physical condition of UHFWC. Inadequate fund collection from local people was considered less effective activity of the project by one-fourth of the managers.

UHFWC providers work round-the-clock to conduct deliveries at UHFWC, which is an exception to the usual service delivery protocol (i.e., usually service providers are rotated to provide round-the-clock services). Two managers asserted that due to an absence of incentive, providers are not motivated to perform optimally.

"To get result, we need to motivate people. Incentive can be a great motivation for working more and it also encourages women to come to UHFWC. If we could provide incentive to women who came for delivery at UHFWC, delivery rate would have increased even more. It is not feasible to take money only from people. It is necessary to provide some money for paying incentive and other activities." - District FP manager 


\section{SERVICE PROVIDER PERSPECTIVES}

From two intervention districts, eight service providers were interviewed $(\mathrm{FWV}=6, \mathrm{SACMO}=2)$. Four service providers were under 40 and remaining four providers were aged 40 years or older. All providers were involved with the implementation activities of the project.

\section{A. Human resources}

It is evident from the in-depth interviews with service providers that with the existing human resources, UHFWCs are able to provide round-the-clock normal delivery service. The majority of service providers stated that they have an assistant and necessary equipment at UHFWCs for providing normal delivery services at night. Only one provider needed an assistant to provide service at night. Clinical readiness including logistics, equipment and supplies were ensured at intervention UHFWCs during the project period. Not all intervention UHFWCs were able to address infrastructural problems. One-fourth of service providers mentioned some infrastructural problems. Providers explained how this project connects pregnant women with UHFWC providers for $24 / 7$ institutional delivery services.

"During this project, situation on institutional delivery has improved a lot. Before the project, most pregnant women in this area preferred delivery at home. This project introduced flyers with my phone number and SACMO's number. When women come to UHFWC for prenatal check-up, I give this flyer to them and advise them to call us whenever labor pain starts or in case of emergency. When pregnant women call me, I advise them to come to UHFWC as needed. Another improvement is that I can perform deliveries at night without any problem as our UHFWC got solar energy system from the Union Parishad during this project." - FWV, age 42, experience 22 years, Chittagong

"Because of this project, now we are at least able to make people understand the importance of institutional delivery. Now, we have delivery kits, and we can provide necessary medicines for at least 10 deliveries. We are very fortunate to have such support. This project motivated us not to perform home delivery. Now, we try our best to counsel and encourage people to come to UHFWC for delivery. The project also motivated us to contact pregnant women over phone. Because of this project, a cordial and direct relationship between pregnant women and UHFWC providers has been established." - FWV, age 56, experience 36 years, Chittagong

Most service providers experienced an increase in maternal health check-ups and normal deliveries at UHFWCs and attributed these improvements partly to the reactivation of Management Committee which is working towards improving UHFWC readiness and 24-hour availability and quality of normal delivery services. Moreover, FWAs in almost all unions refer pregnant women to FWVs and publicize UHFWC's 24-hour normal delivery services while visiting pregnant women door-to-door.

Service providers reported increased monitoring and supervision during the intervention period. They received skilldevelopment lessons/coaching during the supervisory visit. There were several benefits from monitoring as perceived by service providers: on-the-job training on delivery skills, solutions to service-related problems, and counseling skills training on how to motivate pregnant women for institutional deliveries. For example:

"Monitoring and supervision has increased than before. The medical officer (MO-MCH) always calls us and enquires of the number of delivery and whether we face any problems to conduct deliveries. The MO-MCH visits us every month. These visits help us to improve our skills and performance. When they visit our facility, we can ask them how to treat complications that we face while delivering a baby. We also learn from $\mathrm{MO}-\mathrm{MCH}$ in which situations a pregnant woman needs to be referred. The MO-MCH is very supportive." - FWV, age 56, experience 36 years, Chittagong

"Now our medical officer (MO-MCH) and upazila FP manager (UFPO) visit us every month. They check everything-records, registers, delivery room, delivery kit supply, medicine etc. If they detect any lack in our skills, they give us advice and training. When I provide services, the $\mathrm{MOMCH}$ sits beside me and observes my work. These visits help to improve our skills a lot." - FWV, age 42, experience 22 years, Chittagong 


\section{B. UHFWC Management Committee}

A key success of the project lies in the regular participation of local government representatives at the monthly meetings of the UHFWC Management Committee as perceived by seven out of eight service providers. All providers except one further mentioned that Management Committees worked effectively. The majority of the providers highlighted the contribution of the Management Committee to the physical improvement of UHFWC. For example:

"This project helped to strengthen the UHFWC Management Committee. Now we arrange meetings every month and Management Committee members attend the meetings with high enthusiasm. With their support, we painted this UHFWC building. It is a great thing that local people are participating for the improvement of a government facility. Apart from the physical improvement, the delivery performance has improved. The number of deliveries at this UHFWC increased." - SACMO, age 39, experience 8 years, Munshiganj

"Normal delivery has not been performed before in this center. Earlier, there was no supply water and electricity. During this project, the Chairperson of the Management Committee donated a solar system to our facility and fans and other electric goods for the delivery room. As a result, I can now deliver round-the clock." - FWV, age 23, experience 3 years, Chittagong

"Our UHFWC Management Committee is working effectively. We have opened a community fund and collected some money from committee members. The amount is small, but we repaired the water pump motor. If we waited for the authority to repair it, it would take a much longer time and delivery service would have been disrupted. But with the fund's money, we repaired it very quickly." - FWV, age 42, experience 22 years, Chittagong

The contribution of the Management Committee to demand generation through leaflet printing and distribution, public announcements and courtyard meetings was perceived by more than half of the service providers. One service provider from Munshiganj noted lack of BCC activities by Management Committee members and deficiency in initiatives of the Management Committee to bring delivery patients to the UHFWC.

\section{Community fund for emergency maintenance}

Largely, providers expressed concerns with the utility of community fund. The majority of service providers stated limited physical improvement of UHFWCs using community fund. No accumulation of funds after the initial collection was cited as the main reason by the service providers. Half of the service providers considered people's lack of interest in donating money for government facilities as the reason for irregularities in fund accumulation.

Maintaining good physical infrastructure was recommended to attract people's attention for the UHFWC. Involving rich people in the committee was widely conceived as a source for community fund. Some providers stressed on organizing monthly meetings of the UHFWC Management Committee on a regular basis and motivating committee members, particularly local government representatives to contribute and collect fund.

One provider from Chittagong recommended how to increase local people's participation for the community fund after the project.

“Committee members are happy that we involved them in the committee. But many of them were not happy since they were asked to donate money for the fund. As a result, the amount of fund has not increased as expected. To collect fund regularly, we need to introduce monthly contribution by the committee members. The committee members need to change their attitude towards contributing to the community fund and also collect fund from the local people. Besides, we need to approach the elected female members of the Union Parishad, who can collect money from their areas. We need to invite community members in the monthly meeting and ask for their help. We can involve 5-6 local people to motivate other members in the community." - FWV, age 56, experience 36 years, Chittagong 
Reluctance of the Management Committee to use community fund for improving the facility is intense. Providers are fearful of taking the responsibility to use the community fund. One provider from Chittagong noted:

"Spending money means accountability. Nobody wants to be accountable for other's money. Nobody wants to take responsibility. People get afraid easily in such situations. If they spend the money for repair or buying equipment, there is an apprehension that community donors might accuse them for misuse of money. Community members might oppose the use of fund for spending on a governmental building as they donated fund for delivery purpose."- FWV, age 56, experience 36 years, Chittagong

\section{Connecting women with UHFWC providers}

Two-way communication. According to most providers, the use of IEC materials (flyers with FWV's phone number, stickers with the description of services) during counselling at the facility and domiciliary services enabled pregnant women to become aware of $24 / 7$ delivery service at UHFWC. Both at facility and community levels, the mobile phone number of FWV was given to pregnant women which helped to establish a two-way communication system. All service providers found this strategy for publicity highly effective. As a result, FWVs contact pregnant women following the EDD list and counsel and encourage them to come to UHFWC. When needed, pregnant women contact FWVs over the phone and ask for appointment and advice. Service providers were in favor of continuing phone contact with pregnant women after the project ends. Half of them think regular supervision and monitoring will help to continue the two-way communication smoothly.

Strengthening referral linkage. All service providers admitted that referral linkage has been strengthened due to the intervention. They highlighted the effectiveness of referring complicated cases with a slip and publicizing a list of CNG drivers' mobile number at UHFWCs for emergency referral transportation towards strengthening referral system.

\section{E. Reasons for home delivery}

Family members' (older members of the household as well as relatives and neighbors) traditional mindset and misconception was identified as the main reason for women's interest in home delivery by half of the service providers. One fourth of the providers mentioned that it is due to the fulltime presence of relatives, women feel safe at home and want to stay there for delivery rather than go to a hospital. The perception "institutional delivery means cesarean delivery" is the other reason for women's interest in home delivery as stated by a few providers.

\section{F. Client preference for private facilities}

Generally, people choose a private hospital over public hospital in case of referral as observed by the majority of service providers. Half of the providers mentioned enhanced economic condition of the community members for such preference. Three out of eight providers identified a key supply-side problem that prompts women to go to private clinics: unavailability of cesarean delivery provision at the UHFWCs and many UHCs. One provider explained that people do not have monetary problem and they spend money for better service. For example:

"Now-a-days couples do not want many children. Most of them want only two children. So, they spend money for the delivery of only two kids and people are willing and able to spend more money for child birth." - FWV, age 54, experience 20 years, Munshiganj

Not only private provider's advice but also client's interest impacted higher use of private facilities for delivery services. One provider from Munshiganj explained:

"Gynecologists working in this area advice their clients to get admitted at their hospital before the time of delivery. They perform cesarean delivery even if normal delivery is possible, as they can earn a good amount of money from each cesarean delivery. It is a common practice all over the country. Due to this monetary reason, normal delivery rate is low and people go to private clinics since UHFWCs and most UHCs do not have cesarean delivery provision." - SACMO, age 39, experience 8 years, Munshiganj 
"Except one, all deliveries in this area in past few weeks were cesarean. People are more interested in cesarean delivery, so they do not come to UHFWC since we do not have cesarean delivery provision." FWV, age 57, experience 35 years, Munshiganj

Physical amenities, e.g., infrastructure, environment, cleanliness, equipment, supplies, and attendant accommodation, are better in private facilities than public facilities which attract women more towards private clinics. For example:

"People want to avoid public hospitals because of the gatherings. Too many people go to public hospitals so it is difficult to find a bed there. Patients have to wait for long time to get the service. Also, it is hard to obtain release whenever you want and there is no provision for relatives of pregnant women to stay with them. In a private clinic, you can have all these things. You can book a cabin and stay there and you do not have to wait for long." - FWV, age 42, experience 22 years, Chittagong

\section{G. Program effectiveness}

Service providers were asked to identify the effective and less effective sides of the project. The active involvement of local government representatives in the reactivated UHFWC Management Committee was mentioned as the most effective intervention by half of the providers. Half of the service providers could not find any ineffective side in the project. One service provider expressed her disappointment with lack of infrastructural improvement and repair using the community fund. Service providers considered inadequate fund collection from local people as one of the less effective intervention of the project. 


\section{Cost Analysis}

Information on the cost is crucially important to assess the amount of resources needed for the replication the intervention. The purpose of this section is to present the estimate of cost of the intervention and analyze the nature of the cost. The materials for cost analysis included the activity sheets, budget, use of services, and expenditure incurred by each cost item. The project had incurred only fixed cost and recurrent cost; other two categories of inputs, variable and capital, do not exist in this project. The inputs or activities which last for more than one year are considered fixed inputs and those enduring for less than a year are recurrent inputs. Out of the activities orientation meetings, action plan workshops, sensitization meetings, making metal signboards and board-posters, and printing of flyers, brochures and referral slips are under fixed cost category and other activities such as monthly UHFWC Management Committee meeting and EDD phone calls cost fall under the recurrent cost. Total intervention cost is comprised of fixed and recurring costs. The total cost for each of the 24 UHFWCs is calculated at BDT 121,267 of which total fixed cost is BDT 103,067 and recurrent cost is BDT 18,200.

For this project, the amount of increase in the number of users of ANC 3, delivery care, and PNC 1 was estimated as the joint output of the activities. To measure the effect of the intervention, the incremental cost for normal deliveries at the UHFWC was estimated and compared between districts. It is to be noted that normal deliveries have been included in the output as this has been done to estimate the average cost or cost per client who have received any care under the intervention.

Table 8.1 shows the aggregate number of outputs by districts and upazilas and each upazila represents the aggregate performance of 3 intervention UHFWCs. Within Chittagong district output figures is highest in Boalkhali upazila and lowest in Anwara upazila, and within Munshiganj district Tongibari performed best and Sreenagar worst (negative change in output). The effect (changes in normal deliveries) also widely varies by area.

TABLE 8.1 Change in number of users of maternal health services at UHFWCs due to interventions

\begin{tabular}{|c|c|c|c|c|c|c|c|c|c|c|}
\hline \multirow[b]{2}{*}{ Area } & \multicolumn{3}{|c|}{ 2014-15 } & \multirow{2}{*}{$\begin{array}{c}\text { Annual } \\
\text { output } \\
(2014- \\
15)\end{array}$} & \multicolumn{3}{|c|}{ 2015-16 } & \multirow{2}{*}{$\begin{array}{c}\text { Annual } \\
\text { output } \\
\text { (2015- } \\
16)\end{array}$} & \multirow{2}{*}{$\begin{array}{l}\text { Change } \\
\text { in total } \\
\text { output }\end{array}$} & \multirow{2}{*}{$\begin{array}{l}\text { Change } \\
\text { in } \\
\text { normal } \\
\text { delivery }\end{array}$} \\
\hline & $\begin{array}{l}\text { Normal } \\
\text { Delivery }\end{array}$ & ANC 3 & PNC 1 & & $\begin{array}{l}\text { Normal } \\
\text { Delivery }\end{array}$ & ANC 3 & PNC 1 & & & \\
\hline \multicolumn{11}{|l|}{ Chittagong } \\
\hline Anwara & 136 & 110 & 185 & 431 & 192 & 171 & 280 & 643 & 212 & 56 \\
\hline Boalkhali & 285 & 474 & 358 & 1,117 & 367 & 592 & 680 & 1639 & 522 & 82 \\
\hline Patiya & 234 & 301 & 354 & 889 & 312 & 417 & 494 & 1223 & 334 & 78 \\
\hline Sitakunda & 25 & 113 & 105 & 243 & 68 & 180 & 236 & 484 & 241 & 43 \\
\hline Total & 680 & 998 & 1002 & 2,680 & 939 & 1,360 & 1,690 & 3,989 & 1,309 & 259 \\
\hline \multicolumn{11}{|l|}{ Munshiganj } \\
\hline Louhajong & 145 & 190 & 171 & 506 & 98 & 302 & 178 & 578 & 72 & -47 \\
\hline Sreenagar & 34 & 449 & 224 & 707 & 41 & 347 & 216 & 604 & -103 & 7 \\
\hline Tongibari & 63 & 322 & 143 & 528 & 117 & 424 & 214 & 755 & 227 & 54 \\
\hline Shirajdikhan & 115 & 184 & 310 & 609 & 152 & 231 & 333 & 716 & 107 & 37 \\
\hline Total & 357 & 1,145 & 848 & 2,350 & 408 & 1,304 & 941 & 2,653 & 303 & 51 \\
\hline
\end{tabular}

Figure 8.1 presents how much cost (in Bangladesh taka) is needed for increasing one additional maternal health output and delivery output. The comparison between two districts shows a significant difference where incremental cost per delivery output in Munshiganj is five times of Chittagong. In Chittagong, the average total cost for conducting one normal delivery at UHFWC is BDT 5,618, average fixed cost being BDT 4,775 and average recurrent 
cost BDT 843 while in Munshiganj, the average total cost for conducting one additional normal delivery at the UHFWC is BDT 28,533 indicating average fixed cost being BDT 24,251 and average recurrent cost BDT 4,282, which corresponds with higher utilization of UHFWCs for delivery services in Chittagong than Munshiganj as revealed through the endline household survey.

FIGURE 8.1 Basic estimates of cost incurred by the project

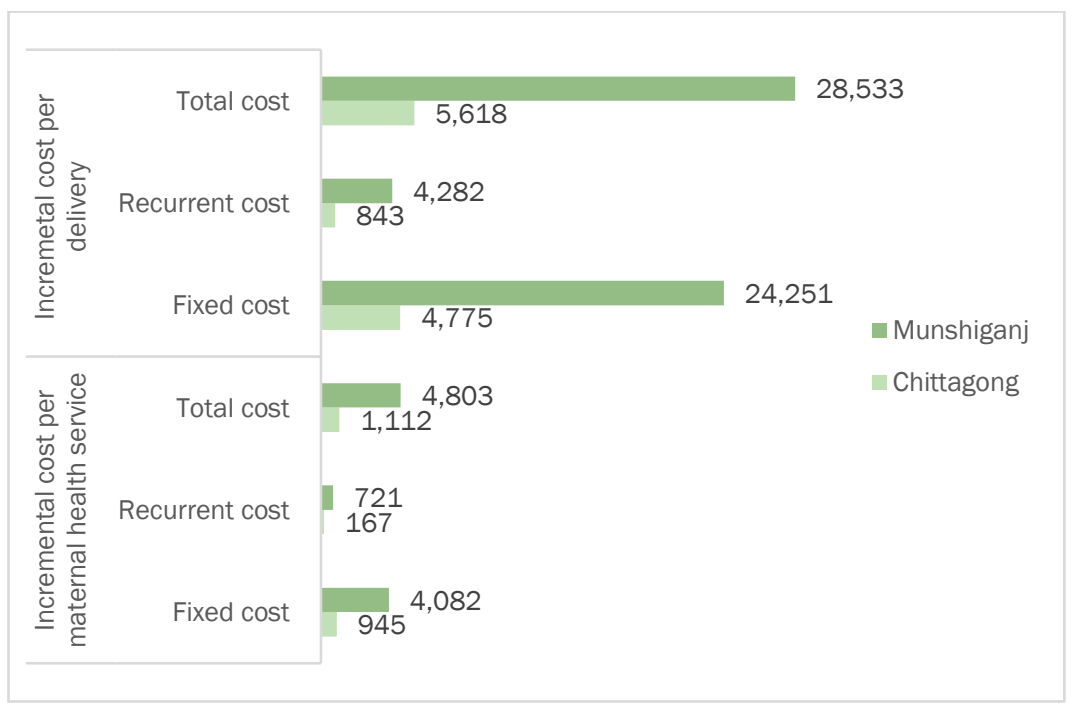

When all maternal health services (ANC 3, delivery and PNC 1) are considered, the average total cost is much lower than the average cost for delivery only. Yet, the incremental cost per maternal health services for Munshiganj is four times of that incurred for Chittagong. In Chittagong, the average total cost for one maternal health output at UHFWC is BDT 1,112 (fixed cost: BDT 945, recurrent cost: BDT 167) while in Munshiganj the average total cost is BDT 4,803 (fixed cost: BDT 4,082, recurrent cost: BDT 721). The gap between Chittagong and Munshiganj for joint maternal health output is less intense than that for delivery output.

The fixed cost comprises of more than 80 percent of the total cost. The fixed cost to be incurred only in the first year (for orientation meetings, action plan workshop, sensitization meetings, metal signboards and board-posters and printing) is estimated at BDT 24,251 (USD 310) for Munshiganj and BDT 4,775 (USD 61) for Chittagong. In the second year and onward, the cost for conducting one additional normal delivery (recurrent cost) at UHFWC would be BDT 843 (USD 11) in Chittagong and BDT 4,282 (USD 55) in Munshiganj (Figure 8.1).

In many unions, output did not increase or increased only marginally during the intervention period and the average cost of service provision is very high. It is likely that due to shorter duration of the intervention the impact of the project has not been fully realized. Of the two districts, Chittagong performed much better in producing output than did Munshiganj. It is evident that the delivery output greatly varies by union. The increase in output is as high as 67 in Kushumpura and 52 in Chorondeep unions in Chittagong. But in some unions, output rather decreased. The decrease is intense in most unions of Louhajong and Sreenagar upazilas in Munshiganj.

\section{FINANCIAL SUSTAINABILITY}

Once the activities are in place and the fixed inputs employed, which is done in the initial period, the project can run for many years without mounting much pressure on the resources since in the following periods only the recurrent costs will be incurred, and the recurrent cost is only a small proportion of the total cost. Second, as time passes, output will increase, so that average fixed cost will decline gradually. There is no variable cost in the project to add to the total cost as output increases. Third, the project is also mobilizing some amount of resources from the community for its functioning. Therefore, it emerges that the project is financially sustainable. 
It is surprising to find that in some UHFWCs in Munshiganj output has declined. Most unions in this district do not belong to the most disadvantaged areas of the country, therefore some antagonistic factors adversely affected the performance to the extent that change in output during the intervention period has become negative. Increasing the utilization of normal delivery services in Munshiganj has not been possible for a combined effect of geographic proximity to the government tertiary-level hospital with good road communication system, availability of private clinics at the union level, and the socio-economic status of the people. Since the positive effect of the intervention is high in most unions in Chittagong, it can be expected that if some special measures are introduced in the lowperforming unions to remove the obstacles, change in output will be positive and this will greatly reduce the average cost of service provision.

Moreover, one encouraging aspect of the intervention is that it has been able to increase support in the community and collect some fund from the local people for renovation and maintenance of the UHFWCs. As Table 8.2 shows, the proportion of contribution to the cost of intervention is quite high in some unions (e.g. Baultoli in Munshiganj and Chorondeep in Chittagong). If such contribution can be collected in all unions, it will considerably reduce amount of money required from the external sources. Considering all these, it can be stated that the prospective financial sustainability of the intervention is high.

TABLE 8.2 Amount of community contribution as percentage of total cost of the interventions

\begin{tabular}{|c|c|c|c|c|c|c|}
\hline District & Upazila & Union & $\begin{array}{l}\text { Intervention } \\
\text { cost }\end{array}$ & $\begin{array}{l}\text { Community } \\
\text { contribution }\end{array}$ & Total cost & $\begin{array}{c}\text { Community } \\
\text { contribution as a } \% \text { of } \\
\text { total cost }\end{array}$ \\
\hline \multirow{10}{*}{ 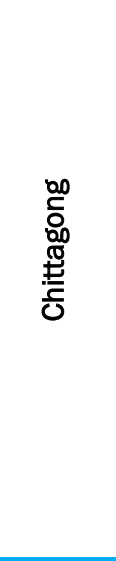 } & \multirow{3}{*}{ Anwara } & Barshot & 121,267 & 55,000 & 176,267 & $31 \%$ \\
\hline & & Boirag & 121,267 & 1,000 & 122,267 & $1 \%$ \\
\hline & & Haildhor & 121,267 & 70,000 & 191,267 & $37 \%$ \\
\hline & \multirow{2}{*}{ Boalkhali } & Chorondeep & 121,267 & 93,500 & 214,767 & $44 \%$ \\
\hline & & Shakpura & 121,267 & 20,000 & 141,267 & $14 \%$ \\
\hline & \multirow{2}{*}{ Patiya } & Chorpathorghata & 121,267 & - & 121,267 & $0 \%$ \\
\hline & & Kushumpura & 121,267 & - & 121,267 & $0 \%$ \\
\hline & \multirow{2}{*}{ Sitakunda } & Shonaichhori & 121,267 & 1,000 & 122,267 & $1 \%$ \\
\hline & & Solimpur & 121,267 & - & 121,267 & $0 \%$ \\
\hline & \multicolumn{2}{|c|}{ District Total } & $1,091,403$ & 240,500 & $1,331,903$ & $18 \%$ \\
\hline \multirow{10}{*}{ 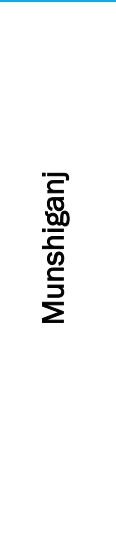 } & \multirow{3}{*}{ Louhajong } & Baultoli & 121,267 & 200,000 & 321,267 & $62 \%$ \\
\hline & & Holdia & 121,267 & 75,200 & 196,467 & $38 \%$ \\
\hline & & Kanakshar & 121,267 & 1,500 & 122,767 & $1 \%$ \\
\hline & \multirow{4}{*}{ Sreenagar } & Atpara & 121,267 & 26,000 & 121,267 & $18 \%$ \\
\hline & & Beertara & 121,267 & 1,000 & 122,267 & $1 \%$ \\
\hline & & Hashara & 121,267 & 76,500 & 197,767 & $39 \%$ \\
\hline & & Ariol Baligaon & 121,267 & 13,000 & 134,267 & $10 \%$ \\
\hline & \multirow[t]{2}{*}{ Tongibari } & Betka & 121,267 & 34,500 & 155,767 & $22 \%$ \\
\hline & & Kamarkhara & 121,267 & 14,800 & 136,067 & $11 \%$ \\
\hline & \multicolumn{2}{|c|}{ District Total } & $1,091,403$ & 442,500 & $1,533,903$ & $29 \%$ \\
\hline
\end{tabular}




\section{Discussions and Conclusions}

The DGFP undertook an initiative to provide 24-hour normal delivery services in their 1,500 upgraded UHFWCs, but these facilities remained largely underutilized for normal delivery services. The DGFP perceived the need for strengthening UHFWCs to provide 24-hour normal delivery services and requested Population Council's technical assistance. Under the guidance of the DGFP, Population Council implemented an operations research study in 24 UHFWCs in Chittagong and Munshiganj districts to test the effectiveness of a model how to address infrastructural and managerial problems that UHFWCs confront to provide 24-hour normal delivery services. Six UHFWCs from Comilla district comparable to the intervention facilities served as control sites. Findings from this OR study provide useful insights to understand the processes needed to provide 24-hour normal delivery services at the UHFWCs.

Interventions were implemented for a period of 12 months. The impact of the interventions was more pronounced in Chittagong than in Munshiganj. Findings in terms of outcomes of the project, relative effectiveness of the interventions, and financial sustainability are discussed below.

\section{IMPACT OF THE INTERVENTIONS}

\section{Awareness of maternal healthcare facilities}

Differences in women's awareness on the sources of pregnancy care and treatment for obstetric complications between two intervention districts are distinct, with Chittagong exhibiting higher awareness. The level of such awareness is lowest in the control district.

Overall, private hospital/clinic is known as the primary source of maternal health services in both intervention and control areas. In the past 12 months, UHFWC has emerged as the most popular source of maternal health services in Chittagong (75\%) while the prominence of private facilities decreased notably from 76 to 41 percent in this district. In other intervention district, UHFWC is second popular source of maternal health services (Munshiganj: $62 \%)$. Awareness on UHFWC as a source of maternal health care is much lower in Comilla (39\%). UHC is another popular source of maternal health services (Chittagong: $56 \%$, Munshiganj: $53 \%$, Comilla: $43 \%$ ) and women's perception about UHCs increased a little over time in the intervention districts alone.

Interventions have resulted in improving the awareness about UHFWC's 24-hour normal delivery services (Chittagong: Baseline 6\%, Endline 40\%; Munshiganj: Baseline 0\%, Endline 31\%). Yet, two-thirds of the women remain ignorant of UHFWC's $24 / 7$ normal delivery services. During the intervention period, at the community level, awareness promotion activities were carried out through fieldworker's doorstep visits. No courtyard meetings were organized by the fieldworkers. Further increase in the awareness require strengthening of BCC activities in the community so that every pregnant woman can be informed.

Apart from the medical college hospital, Upazila Health Complexes are widely known as sources of complications management care to women in both intervention districts. UHFWC is another popular source of treatment for delivery complications, particularly in two intervention districts (Chittagong: 59\% and Munshiganj 37\%) and UHFWC awareness increased in both intervention areas. Although the awareness on UHFWC as a source of treatment for delivery complications is high in Chittagong, the UHFWCs do not have the provision for basic EmOC services. Paradoxically, government facilities that are well equipped to treat delivery complications are known to a small proportion of women. For example, women were ignorant of district-level facilities, namely, District Hospital and MCWC, as the source of treatment for complications. 


\section{Utilization of antenatal care}

Seeking first antenatal care is almost universal in the intervention areas which remained almost the same over time while the control area witnessed a decrease from 95 to 82 percent in the past 12 months. The use of public facilities for antenatal care is higher in the intervention areas (Intervention: 40\%, 44\%, Control: 31\%). In intervention areas, of women who received ANC from public facilities, over 70 percent sought the service from local facilities (UHFWCs and Community Clinics) while 57 percent in the control district so reported. UHFWC is mainly utilized for ANC, primarily in the intervention areas (Intervention: 68\%, 56\%; Control: 44\%). The use of community-level facilities for ANC was extremely low.

Chittagong is credited for near-saturation in the use of three or more ANC while such practice is lowest in the control district (Chittagong: 91\%, Comilla: 65\%). This is an important development as it is established that the higher the number of antenatal check-ups the higher the likelihood of facility-based deliveries.

\section{Utilization of delivery services}

Large differences exist in the use pattern of delivery services between intervention and control areas as well as between intervention districts. Findings suggest a higher rate of institutional delivery in the intervention districts $(72 \%, 79 \%)$ than the control district (53\%). Of the intervention districts, the share of private facilities in institutional deliveries is much higher in Munshiganj (70\%) than in Chittagong (36\%). In Chittagong, one-third of the public-sector deliveries are conducted at the UHFWCs, which is nearly three folds of the control UHFWCs. Chittagong is also credited for the largest increase in the UHFWC contribution to institutional deliveries (from $24 \%$ to $33 \%$ ). The project had limited impact in increasing the use of UHFWCs in other intervention area, Munshiganj (i.e., an increase from $10 \%$ to $14 \%$ ). Besides, Chittagong is credited for another important development which is reflected in the large decrease in the proportion of women of seeking care for delivery complications at home (from $20 \%$ to $6 \%$ ).

An important development is the extremely high use of medically trained providers for delivery services in both intervention districts, more pronounced in Munshiganj (82\%), which is nearly two folds of national average. Among medically trained providers, doctors were mostly used for delivery services across sites, corresponding the higher rate of cesarean deliveries.

A stark difference exists between two intervention districts in terms of types of delivery. Women in Chittagong were more likely to undergo normal deliveries (77\%), while cesarean deliveries were more widespread in Munshiganj (58\%), which reflects greater affordability of women in Munshiganj to seek cesarean deliveries and lack of private provider's interest in normal deliveries. The higher rate of cesarean deliveries in Munshiganj also reveals weaknesses in the clinical monitoring mechanism of the government.

Despite cost of receiving cesarean deliveries at private facilities is two folds of public facilities (BDT 23,485 vs. BDT 12,772), women in Munshiganj were more likely to use private facilities than public facilities, which indicates the better environment and quality of services at the private facilities. A composite quality score for client satisfaction on delivery services substantiates the women preference for private facilities. The public-private gap in client satisfaction on delivery services is evident in Munshiganj, in favor of private facilities (public: 0.66 , private: 0.75 ).

Qualitative findings explain the reasons for client preference for private facilities. People choose private hospitals over public hospitals as physical amenities, e.g., infrastructure, environment, cleanliness, equipment, supplies, and attendant accommodation, are better in private facilities than in public facilities. The unavailability of cesarean delivery provision at the UHFWCs and many upazila-level government facilities is the key supply-side problem that prompts women to go to private clinics. Enhanced economic condition of the people is largely accounted for client's preference for private facilities.

It is surprising to find that in some UHFWCs in Munshiganj delivery output has declined. Increasing the utilization of normal delivery services at many UHFWCs in Munshiganj has not been possible for a combined effect of geographic 
proximity to the government tertiary level hospital with good road communication, availability of private clinics at the union level, and the affordability of households to seek expensive care at private facilities.

In the intervention districts, the likelihood among poor women in taking delivery care at home has decreased over time, yet it is more pronounced in Munshiganj. In Munshiganj, women from the poorest wealth group is almost three times as likely to deliver at home as their counterpart from the richest wealth group (Equity Ratio=2.75), which may be due to the fact that poor women were not aware of UHFWC's 24 -hour normal delivery services.

\section{Utilization of postnatal care}

Regardless of the intervention exposure, the proportion of women receiving PNC increased remarkably (Chittagong: 54-75\%, Munshiganj: 46-78\%, Comilla: 26-54\%). The improvement in the utilization of postnatal care within two days after birth is encouraging which indicates that provider utilized the opportunity to perform postnatal check-ups immediately after birth. Among the public-sector facilities, low use of UHFWCs for postnatal care (Chittagong: 34\%, Munshiganj: 14\%, Comilla: 14\%) and non-use of Community Clinics indicate that brining services to the proximity of women's home is not adequate to ensure their utilization by community people. For any consultation services, the full-time availability of providers remains important to clients, which UHFWCs need to ensure.

After a 12-month period, the use of contraception remains almost the same in the intervention areas, with a small change in method mix, which was caused by an increase in the use of long-acting methods (IUDs and implants). The control district experienced a 13 percentage point decrease from the level of 58 percent use of contraception.

\section{PROGRAM EFFECTIVENESS}

It is evident from the perspectives of both program managers and service providers that the increase in maternal health check-ups and normal deliveries at UHFWCs was considered as the outcome of intervention activities related to community mobilization, human resources management, and referral connectivity.

- Community monitoring and fund mobilization. UHFWC Management Committees were reactivated in 18 unions so that community monitoring and resource mobilization through active community participation can be ensured. UHFWC Management Committees in Chittagong were more successful in conducting meetings than Munshiganj. Financial contribution to the community fund is lower in Chittagong compared with Munshiganj.

A key success of the project lies in the regular participation of local government representatives at the monthly meetings of the reactivated UHFWC Management Committee. The commitment of SACMO and FWV was the key to keep the Committee active. Another encouraging aspect of the community mobilization intervention is the introduction of the community fund through which local people, primarily UHFWC Management Committee members and bazaar committees, contribute to improve the physical infrastructure of UHFWCs. Using the community fund, UHFWC Management Committees succeeded in carrying out civil works for UHFWCs, emergency maintenance related to water and electricity supply, and purchasing essential medical equipment for the labor room of UHFWCs.

Initially, UHFWC Management Committee members were more enthusiastic and made large contributions to their community fund, but in the later months of the intervention the interest of community members waned. Unfortunately, the impact of community mobilization activities is little known to the women (14\%), which indicates limited role of fieldworkers in informing women about the community fund.

Program managers recommended three steps to increase local people's participation and to continue the fund after the project period: local-level advocacy to build ownership among community members for the 
management of UHFWCs; active role of UHFWC providers to organize monthly meetings of the UHFWC Management Committee on a regular basis; and create demand for facility-based delivery.

- Improved monitoring and supervision. Monitoring and supervision has increased during the intervention period. In addition to conducting regular monthly visit to UHFWCs, the medical officer (MO-MCH) enquires of the number of deliveries and whether FWVs face any problems to conduct deliveries. FWVs receive skilldevelopment lessons/coaching during the supervisory visit. Particularly, they learn from MO-MCH how to treat complications that they face while delivering a baby and when to refer a pregnant woman.

Improvements in service delivery occurred to UHFWCs as an outcome of the introduction of quarterly review meetings. Perceived benefits of the review meetings were: the meetings inspired service providers to increase their effort for delivery service, increased supervision and monitoring by managers, identified and addressed gaps in UHFWC readiness, and improved service quality and quantity of UHFWCs.

- Strengthening referral linkage. Both at facility and community levels, the mobile phone number of FWV was given to pregnant women which helped to establish a two-way communication system. All service providers found this strategy for publicity highly effective. FWVs contact pregnant women following the EDD list and counsel and encourage them to come to UHFWC. When needed, pregnant women contact FWVs over the phone and ask for an appointment and advice.

The introduction of referral slip containing information on client's name, age, diagnosis, and reason of referral allows pregnant women to receive more attention and importance at higher-level facilities and helps to expedite client's treatment at referral facilities. The other activity that contributed to strengthen referral linkage is: a list of CNG drivers' mobile number was made available at UHFWCs for emergency referral transportation.

However, both program managers and service providers expressed concerns on the lack of clinical readiness of the UHFWCs, limited utility of community fund, and women's preference for expensive services at private facilities.

- Provision of delivery complications management care. Both program managers and service providers highlighted the absence of the provision for delivery complications management as the key deficiency in the clinical readiness for providing delivery services. As there is no provision for surgical interventions at UHFWC, the availability of a vehicle to send patient to Upazila Health Complex or District Hospital has been emphasized.

- Irregularities in fund accumulation and low use of community fund. Reluctance of UHFWC Management Committee to use community fund for improving the facility is intense. Providers are fearful of taking the responsibility to use the community fund. Physical improvements of UHFWCs made through the use of the community fund were much less than it was anticipated by the service providers. No accumulation of fund after initial collection was observed in most unions. People's lack of interest in donating money for government facilities emerged as the key reason for irregular collection of community fund.

- Preference for private facilities. Both demand and supply side factors prompt women to seek services from private than public facilities. People choose private hospital over public hospital as physical amenities, e.g., infrastructure, environment, cleanliness, equipment, supplies, and attendant accommodation, are better in private facilities than public facilities. Enhanced economic condition of the people is accounted for people's preference for private facilities.

Unavailability of cesarean delivery provision at UHFWCs and many upazila-level government facilities is the key supply-side problem that prompts women to go to private clinics. Availability of private clinics in the proximity is another reason for choosing private clinics instead of public facilities. 


\section{FINANCIAL SUSTAINABILITY}

Information on the cost of the intervention is crucially important to assess the amount of money needed for the intervention. The comparison between two intervention districts reveals a significant difference where incremental cost per delivery output in Munshiganj is five times of Chittagong as Chittagong performed much better in producing output than did Munshiganj. In Chittagong, the average total cost for conducting one additional normal delivery at the UHFWC is BDT 5,618 while it is much higher in Munshiganj (BDT 28,533). The fixed cost comprises of more than 80 percent of the total cost. The fixed cost to be incurred only in the first year is estimated at BDT 24,251 for Munshiganj and BDT 4,775 for Chittagong. In the second year and onward, the cost for conducting one normal delivery (recurrent cost) at the UHFWC would be BDT 843 (USD 11) in Chittagong and BDT 4,282 (USD 55) in Munshiganj.

One encouraging aspect of the intervention is that it has been able to increase support in the community and collect some fund from the local people for renovation and maintenance of UHFWCs. The proportion of contribution to the cost of intervention is quite high in some unions. If such contribution can be collected in all unions, it will considerably reduce amount of fund required from the intervention. Considering all these, it can be stated that the prospective financial sustainability of the intervention is high. 


\section{References}

Howlader, S.R. 2011. "Costing and economic analysis of strengthening union level facility for providing normal delivery and newborn care services in Bangladesh." Dhaka: Population Council.

National Institute of Population Research and Training (NIPORT), Mitra and Associates, ICF International. 2016. Bangladesh Demographic and Health Survey 2014. Dhaka, Bangladesh and Calverton, Maryland, USA: NIPORT, Mitra and Associates, and ICF International.

Rutstein, S., K. Johnson. 2004. The DHS Wealth Index. DHS Comparative Report 6. Calverton, MD: ORC Macro.

Talukder, M.N., U. Rob, A.K.M.Z.U. Khan, A.K. Baidya, M.M.R. Khan, N. Sultana. 2011. "Strengthening union level facility for providing normal delivery and newborn care services." Facility Assessment Report. Dhaka: Population Council.

Talukder, M.N., U. Rob, A.K.M.Z.U. Khan, F.R. Noor, S. Roy, A.F. Noor. 2015. “Union Health and Family Welfare Centers in Chittagong and Munshiganj: Are they ready to provide 24-hour normal delivery services?" Facility Assessment Report. Dhaka: Population Council.

Watkin, D.R., S. Rutstein, R.P. Pande, A. Wagstaff. 2000. Socio-economic Differences in Health, Nutrition and Poverty. HNP/Poverty Thematic Group of the World Bank. Washington, DC: World Bank. 


\section{Appendixes}

\section{APPENDIX 1: BACKGROUND CHARACTERISTICS OF RESPONDENTS}

TABLE A Socio-demographic characteristics of the respondents (in percent)

\begin{tabular}{|c|c|c|c|c|c|c|}
\hline \multirow[t]{3}{*}{ Characteristic } & \multicolumn{4}{|c|}{ Intervention } & \multirow{2}{*}{\multicolumn{2}{|c|}{$\begin{array}{l}\text { Control } \\
\text { Comilla }\end{array}$}} \\
\hline & \multicolumn{2}{|c|}{ Chittagong } & \multicolumn{2}{|c|}{ Munshiganj } & & \\
\hline & Baseline & Endline & Baseline & Endline & Baseline & Endline \\
\hline \multicolumn{7}{|l|}{ Age } \\
\hline 19 years or below & 10.7 & 8.3 & 10.1 & 11.9 & 11.0 & 9.5 \\
\hline $20-24$ & 43.9 & 42.1 & 34.6 & 36.6 & 32.4 & 42.3 \\
\hline $25-29$ & 29.4 & 31.6 & 30.2 & 28.7 & 30.0 & 27.2 \\
\hline $30-34$ & 13.5 & 14.8 & 18.6 & 18.0 & 21.8 & 16.7 \\
\hline $35-39$ & 2.5 & 3.1 & 5.7 & 4.4 & 4.7 & 4.1 \\
\hline 40 years and above & 0.0 & 0.1 & 0.8 & 0.4 & 1.0 & 0.3 \\
\hline Mean age (year) & 24.5 & 24.9 & 25.7 & 25.1 & 25.8 & 24.9 \\
\hline $\begin{array}{l}\text { Mean age of respondent's husband } \\
\text { (year) }\end{array}$ & 33.0 & 33.2 & 34.3 & 33.2 & 33.7 & 32.9 \\
\hline Mean age at first pregnancy (year) & 20.8 & 21.1 & 21.2 & 20.9 & 20.1 & 20.8 \\
\hline \multicolumn{7}{|l|}{ Education of respondents } \\
\hline Never attended School & 7.0 & 5.3 & 6.2 & 5.3 & 4.2 & 2.6 \\
\hline Incomplete Primary & 6.5 & 9.5 & 12.5 & 11.8 & 4.7 & 4.4 \\
\hline Complete Primary 1 & 12.6 & 11.7 & 15.2 & 10.6 & 12.4 & 8.7 \\
\hline Incomplete Secondary & 52.5 & 52.7 & 49.2 & 52.9 & 53.7 & 57.4 \\
\hline Complete Secondary2 & 12.5 & 10.8 & 10.0 & 11.4 & 15.8 & 16.4 \\
\hline More than Secondary & 8.9 & 10.0 & 6.9 & 8.0 & 9.2 & 10.5 \\
\hline Mean education (year) & 7.4 & 7.4 & 6.9 & 7.2 & 7.8 & 8.9 \\
\hline $\begin{array}{l}\text { Mean education of respondent's } \\
\text { husband (year) }\end{array}$ & 9.7 & 10.4 & 9.1 & 10.4 & 11.3 & 9.5 \\
\hline \multicolumn{7}{|l|}{ Number of living children } \\
\hline One & 39.1 & 35.0 & 35.7 & 38.6 & 23.4 & 33.6 \\
\hline Two & 35.6 & 37.2 & 34.9 & 37.1 & 34.7 & 32.1 \\
\hline Three or more & 9.4 & 10.2 & 9.5 & 8.0 & 17.5 & 11.33 \\
\hline Mean number of children & 1.94 & 2.02 & 2.02 & 1.93 & 2.37 & 2.13 \\
\hline \multicolumn{7}{|l|}{ Wealth quintile } \\
\hline Lowest & 19.8 & 17.4 & 27.2 & 22.5 & 14.7 & 11.3 \\
\hline Second & 19.7 & 18.5 & 25.7 & 26.5 & 20.3 & 13.1 \\
\hline Middle & 20.4 & 24.9 & 14.9 & 18.4 & 17.4 & 19.0 \\
\hline Fourth & 24.4 & 26.4 & 14.7 & 16.1 & 16.8 & 18.9 \\
\hline Highest & 15.7 & 12.8 & 17.5 & 16.5 & 30.8 & 37.7 \\
\hline $\mathrm{N}$ & 783 & 772 & 787 & 790 & 380 & 390 \\
\hline
\end{tabular}

1 Primary complete is defined as completing grade 5.

2 Secondary complete is defined as completing grade 10. 


\section{APPENDIX 2: QUALITY SCORE INDICATORS FOR ANTENATAL CARE (16)}

\section{Responsiveness}

Ensured oral and visual privacy

Listened carefully about the problems of the client

Explained client's enquiry/problem elaborately

\section{Physical examination}

Measured client's weight

Measured client's height

Measured blood pressure

Performed /referred for blood test

Performed /referred for urine test

Palpated abdomen for fetal presentation

Performed internal examination for vaginal discharge

Checked woman's eye for anemia

Performed /referred for ultra-sonogram

\section{Prevention and case management}

Informed regarding the complications during delivery

Informed regarding referral services if the complications occur during delivery

Advised about eating nutritious food

Both advised and provided medicine during delivery 


\section{APPENDIX 3: QUALITY SCORE INDICATORS FOR DELIVERY SERVICE (17)}

\section{Responsiveness}

Wanted to know your problem(s)

Listen to your problem(s) attentively

Explained your problem(s) elaborately

Maintained audio and visual privacy while providing services to you

Waited for long time

\section{Prevention and case management}

Informed about the complications which can occur after delivery

Informed about where to go if experience complications after delivery

Advised about breast feeding and care of breast

Suggested to eat nutritious food

Suggested for child immunization

Advised on child spacing and family planning

Asked for a follow up visit

\section{Level of services}

Terms of cleanliness

Availability or receiving medicine from the service center/provider

Presence of service providers at the health facility

Availed bed (seat) during your stay at the facility

Paid money for any other reason except receiving services 


\section{APPENDIX 4: QUALITY SCORE INDICATORS FOR POSTNATAL CARE (29)}

\section{Responsiveness}

Ensured oral and visual privacy

Explained client's enquiry/problem elaborately

Ensured supportive behavior for client's faith on service provider

Waiting long time during PNC services

\section{Physical examination}

Checked the woman's pulse

Measured blood pressure

Measured body temperature

Checked dehydration

Checked anemia

Examine swelling in feet and hand/edema

Examine breast and breast nipple

Checked length of cervix

Checked abdominal pain

Checked vaginal bleeding since birth

Checked smell of vaginal discharge

Checked anything unusual coming through vagina

Checked the stich of episiotomy

Checked the condition of perineum

Checked if the mouth of the uterus is torn

\section{Prevention and case management}

Advised about breast feeding and caring of the breasts

Advised about eating nutritious food

Advised and provided medicine of anemia

Advised and gave vitamin 'A' capsule to take

Advised a woman how to breast feed the baby

Advised to follow up check-ups

Advised regarding the vaccination of baby

Advised regarding the complications after delivery

Advised regarding referral services if there is any complications after delivery

Asked about interval of delivery and family planning services 
